\title{
Effect of Donor-Acceptor Substitution on Optoelectronic Properties of Conducting Organic Polymers
}

\author{
Ulrike Salzner* \\ Department of Chemistry, Bilkent University, 06800 Bilkent, Ankara, Turkey
}

ABSTRACT: The impact of donor-acceptor substitution on optical and electronic properties of conducting polymers was investigated with time-dependent density functional theory (TDDFT). A series of donor-acceptor systems with thiophene, 3,4-ethylenedioxythiophene, and pyrrole as donors and 3,4difluorothiophene, diketopyrrolopyrrole, 2,1,3-benzothiadiazole, 4-dicyanomethylene- $4 H$-cyclopenta $\left[2,1-b ; 3,4-b^{\prime}\right]$ dithiophene, and indeno[1-2b]-fluorene-6,12-dimalonitrile as acceptors as examples of donor-acceptor systems with increasing donoracceptor character was studied. Spectral properties were ana-

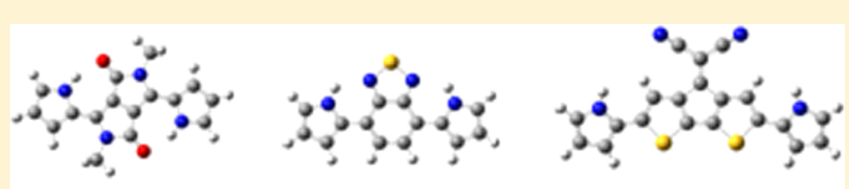
lyzed in terms of differences in ionization potentials and electron affinities of donors and acceptors, charge separations between donors and acceptors in ground and excited states, and electron distribution in the acceptor units. A shift in electron density away from the backbone caused by some of the acceptors correlates with localization of the conduction band on the acceptor. Localization does not correlate with energy level differences between donor and acceptor. Localization results in shift of oscillator strength from the HOMO-LUMO peak to a higher energy feature where the first delocalized orbital acts as the acceptor. The "camel back" absorption with two equally strong peaks that gives rise to green polymers is the intermediate case associated with partial localization of the conduction band. Stronger localization causes the HOMO-LUMO band to almost vanish.

\section{INTRODUCTION}

The donor-acceptor concept ${ }^{1}$ is one of the most successful approaches to tailoring band gaps of conjugated polymers for application in light emitting diodes (LEDs), ${ }^{2-11}$ organic field effect transistors (OFETs), ${ }^{12-19}$ and organic photovoltaic devices (OPVs). ${ }^{20-59}$ The extensive interest in the concept started with Havinga et al.'s original idea that donor-acceptor systems have small band gaps and large band widths. ${ }^{1}$ The band structures of donor-acceptor systems turned out to be more complicated, however. While band gaps can be reduced by combining different donors and acceptors, band widths do not increase and may actually decrease substantially. ${ }^{60-62}$ Reduced bandwidth is indicative of charge carrier localization and therefore low charge carrier mobility. Unexpected experimental findings of low electron mobility in 3,4-ethylenedioxythiophene (EDOT)-4-dicyanomethylene-4H-cyclopenta[2,1- $\left.b ; 3,4-b^{\prime}\right]$ dithiophene $(\mathrm{CDM})^{63,64}$ and lack of a photoresponse in photoconductivity spectroscopy in cyclopentadienone systems ${ }^{65}$ are the consequence of localization of the conduction band states. Although it is more common for localization to occur in the conduction band, localized valence bands ${ }^{66}$ have been observed as well.

Localization reduces spatial overlap between ground and excited state compared to that of homopolymers with delocalized valence and conduction bands. ${ }^{67}$ It was shown theoretically for fluorene containing donor-acceptor systems that the decreased spatial overlap between the highest occupied molecular orbital (HOMO) and lowest unoccupied molecular orbital (LUMO) leads to lower intensity of the first excited state which is a HOMO-LUMO transition. The oscillator strength shifts to a second peak that arises from skipping the states of the localized conduction "band", transferring the electron into states that resemble the $\pi^{*}$ levels of homopolymers. ${ }^{68,69}$ In certain donoracceptor systems, the two absorption bands have similar intensity and fall into the visible range. Simultaneous absorption of red and blue gives rise to green polymers. ${ }^{70-80}$

Intensive research on OFETs and OPVs in recent years has produced a large amount of experimental data on different donor-acceptor systems and has established empirically the most suitable combinations of donors and acceptors for specific applications. Nonetheless, there is still no general consensus regarding the nature of the dual band absorption, ${ }^{80}$ and the dependence of relative oscillator strengths and the nature of donor and acceptor have not been studied systematically. Therefore, electronic structure changes during excitation in a series of donor-acceptor systems were analyzed with the aim of developing design rules for donor-acceptor systems suitable for OPVs and OFETs.

\section{METHODS}

Donor-acceptor monomers were assembled by symmetrically flanking the acceptors with one donor on each side (Scheme 1). As donors thiophene (TH), 3,4-ethylenedioxythiophene (EDOT), and pyrrole (PY) are employed. The acceptors are 3,4-difluorothiophene (FTH), diketopyrrolopyrrole (PYPY), 2,1,3-benzothiadiazole (BT), CDM, and

Received: July 18, 2014

Published: October 1, 2014 
Scheme 1. Structures of Monomers at B3P86-30\%/6-31G*
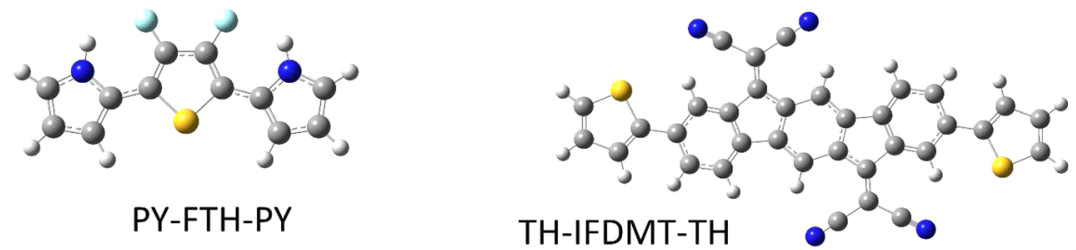

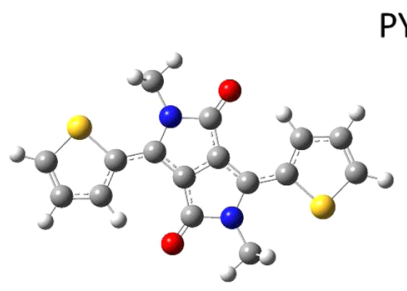

TH-PYPY-TH

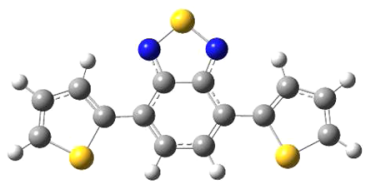

TH-BT-TH

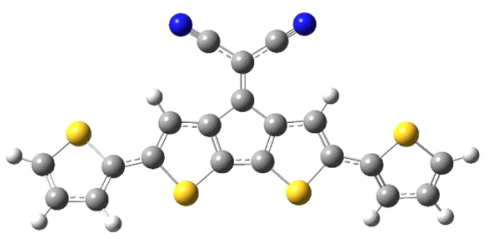

TH-CDM-TH

PY-FTH-PY

TH-IFDMT-TH

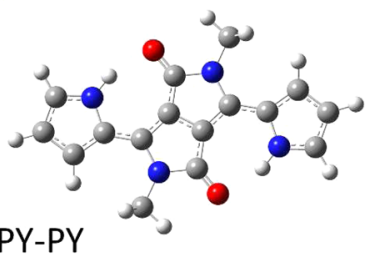

EDOT-PYPY-EDOT

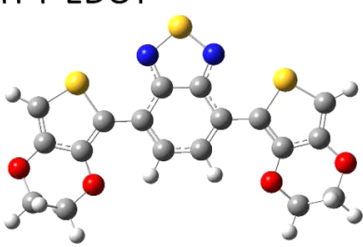

EDOT-BT-EDOT

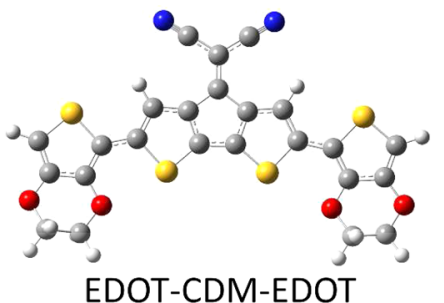

PY-PYPY-PY

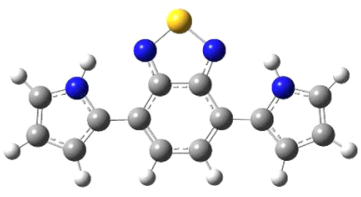

PY-BT-PY

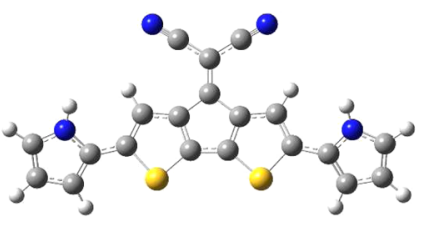

PY-CDM-PY indeno[1-2b]-fluorene-6,12-dimalonitrile (IFDMT). For all monomers, the correct relative orientation of donor and acceptor (cis or trans) was determined. Structures of oligomers with 1-4 and, in some cases, 6 repeat units were optimized without enforcing planarity. With the exception of TH-IFDMT-TH oligomers, all systems were found to be either planar or almost planar with very small planarization energies.

Extrapolation to polymers was done with second degree polynomial fitting to account for convergence at long chain length. Inclusion of hexamers increases polymer band gaps obtained by extrapolation compared to those predicted with tetramers. The differences do not exceed $0.04 \mathrm{eV}$, however. In any case, extrapolation with few oligomers tends to underestimate polymer band gaps. Extrapolated peak positions are therefore lower bounds. In addition, disorder in the thin films mimics properties of shorter oligomers.

HOMO and LUMO levels of tetramers are already close to those of polymers and the lower valence band and the upper conduction band edge converge even faster with increasing chain length. Therefore, the energy levels of tetramers are used as models for polymer bands and the terms "band gap" and "bandwidth" is used also for oligomers.

Excited states up to about $4 \mathrm{eV}$ were calculated using timedependent density functional theory (TDDFT). Charges in ground and excited states were assessed with natural population analysis (NPA). ${ }^{81}$ Because certain excited states of donoracceptor systems have charge-transfer character, the performances of a global and a range-separated hybrid are compared. For structure optimizations and excited state calculations the global hybrid B3P86-30\%, ${ }^{82-84}$ which contains $30 \%$ of exact exchange and the range-separated hybrid functional, wB97XD, ${ }^{85}$ with $22 \%$ of short-range, $100 \%$ of long-range exact exchange and a rangeseparation parameter of $0.2 \mathrm{Bohr}^{-1}$ were used. The particular choice of the two functionals is based on a previous detailed evaluation of density functional performance regarding properties of $\pi$-conjugated systems. ${ }^{86}$

The advantage of $\mathrm{wB} 97 \mathrm{XD}$ is that it produces orbital energies that are good estimates of ionization energies (IP)s and electron affinities (EA)s for homopolymers. ${ }^{86}$ For the donor-acceptor systems studied here, gas phase IPs and EAs are not available. Therefore, the accuracy of the orbital energies could only be checked against IPs and EAs calculated as energy differences between neutral species and ions ( $\triangle$ SCF IPs and EAs). The negative HOMO energy overestimates the IPs by $0.19-0.28 \mathrm{eV}$ and underestimates EAs by $0.04-0.25 \mathrm{eV}$. There is no increase in the error with increasing chain length, which is important for extrapolation. Orbital energies and band structures are therefore discussed using the $\mathrm{wB} 97 \mathrm{XD}$ values throughout the paper.

Overestimation of excitation energies and IPs and underestimation of EAs can be improved by tuning of the range-separation parameter. ${ }^{87-91}$ However, DFT $\Delta$ SCF IPs of conjugated oligomers decrease too fast with increasing chain length, so that the correct chain length dependence would require increasing the amount of HF exchange. ${ }^{86}$ In contrast, studies on tuning have revealed that the range-separation has to decrease with increasing system size to match orbital energies with $\Delta$ SCF IPs. ${ }^{86,90}$ It is therefore impossible to reproduce the correct IPs of large conjugated systems with tuning. For this reason, a constant rangeseparation parameter was employed in the present study.

Solvent effects on the excitation energies were evaluated for 4-EDOT-BT-EDOT with both density functionals. Using the PCM method and acetonitrile as the solvent, excitation energies 
decrease by $0.04 \mathrm{eV}$ and there is practically no influence on oscillator strengths. Solvent effects are therefore not considered any further. Vibronic structures of absorption spectra of $\pi$-systems were investigated theoretically by Grimme and co-workers. ${ }^{92,93}$ In general, the vertical excitation occurs at about $0.2-0.4 \mathrm{eV}$ above the $0-0$ transition and lies in the vicinity of the third vibronic peak. Vibrationally resolved spectra of polymers are generally not available and measured peaks are very broad. $\varepsilon_{\max }$ is quite ill-defined, theoretically and experimentally, but is generally blue-shifted by a couple tenths of an electronvolt with respect to the onset of absorption. Therefore, vertical excitation energies empolyed here, are expected to be close to experimental absorption maxima (within $\sim \pm 0.2 \mathrm{eV}$ ).

All calculations were done with the $6-31 G^{*}$ basis set and the Gaussian 09 program. ${ }^{109}$ UV spectra are prepared with GabEdit. $^{94}$

\section{RESULTS}

Performance of the B3P86-30\% and wB97XD Density Functionals. To assess the quality of theoretical predictions, Figure 1 compares results with the B3P86-30\% and wB97XD functionals to available experimental absorption energies $\left(\varepsilon_{\max }\right.$ values) of monomers and polymers. Because polymer spectra are measured on thin films and peaks are very broad, a perfect agreement between theory and experiment should not be expected. Figure 1 shows, however, that the trend in absorption energies is reproduced well with both functionals. B3P86-30\% tends to underestimate, and ${ }^{\mathrm{w} B 97 \mathrm{XD}}$ tends to overestimate experimental absorption energies. Interestingly, there seems to be no advantage in using the range-separated functional for reproducing the low energy charge-transfer states. In fact, the underestimation with B3P86-30\% is smallest for these states. This indicates that there is enough spatial overlap between ground and excited state that the problems of TDDFT with through space interactions are not encountered. In addition, the overdelocalization with global hybrids is reduced because of partial localization of the conduction bands as explained below.
For the second absorptions, there is again little underestimation with B3P86-30\% and here the global hybrid performs clearly better than the range-separated functional. Similar behavior was already observed for higher excited states of open-shell systems. ${ }^{86}$ It seems possible that higher energy diffuse states are affected more by high amounts of long-range exact exchange than more compact low energy excited states and that $100 \%$ of exact exchange is too much.

In Figure 2, wB97XD and B3P86-30\% absorption spectra of monomers through hexamers and extrapolated polymer spectra of EDOT-BT-EDOT and PY-BT-PY are shown. Experimental onset of absorption and $\varepsilon_{\max }$ of polymer thin films ${ }^{78}$ are given as vertical bars. Figure 2 shows that the match between experiment and $\mathrm{B} 3 \mathrm{P} 86-30 \%$ spectra is quite reasonable tending to be on the low side. With wB97XD, the peaks are shifted to higher energy and lie outside the range of the observed absorptions. WB97XD also tends to put less oscillator strength into the high energy absorption. Experimental spectra of the two systems exhibit two strong absorptions so that wB97XD seems to underestimates the strength of the high energy peaks. Because the B3P86-30\% and wB97XD spectra are otherwise very similar and B3P86-30\% has no problems with the low lying charge-transfer states, only B3P86-30\% spectra are shown hereafter.

IPs and EAs of Donors and Acceptors. In the original publication on the donor-acceptor concept, the donor-acceptor character was associated with the energetic shift of the bands of the donor and acceptor homopolymers relative to one another. ${ }^{1}$ Because donor-acceptor systems contain alternating donor and acceptor monomer units and not alternating polymers, it appears more suitable to compare the relative energies of the monomer units. WB97XD/6-31G* orbital energies that correspond directly to IPs and EAs of the donor and acceptor monomers are summarized in Table 1. Based on orbital energies, donor strength increases in the order $\mathrm{TH}<\mathrm{EDOT}<\mathrm{PY}$, and acceptor strength increases in the order FTH $<\mathrm{PYPY} \approx \mathrm{BT}<\mathrm{CDM}<\mathrm{IFDMT}$. The HOMO energies of donors and acceptors differ by up to $1.3 \mathrm{eV}$, the LUMO energies by up to $5.2 \mathrm{eV}$. Thus, energy differences are much more pronounced in conduction than in valence bands.

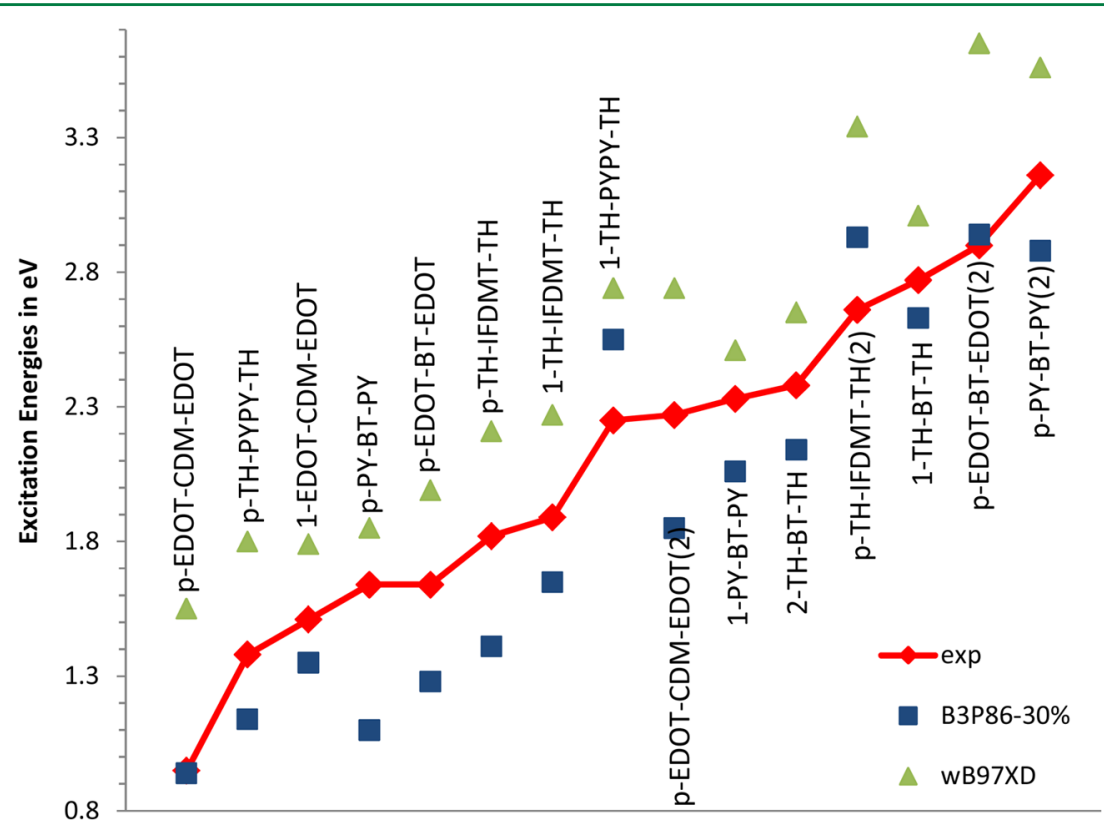

Figure 1. Comparison between predicted and measured $1-1^{\prime}$ and $1-x^{\prime}$ (marked with (2)) excitation energies. 

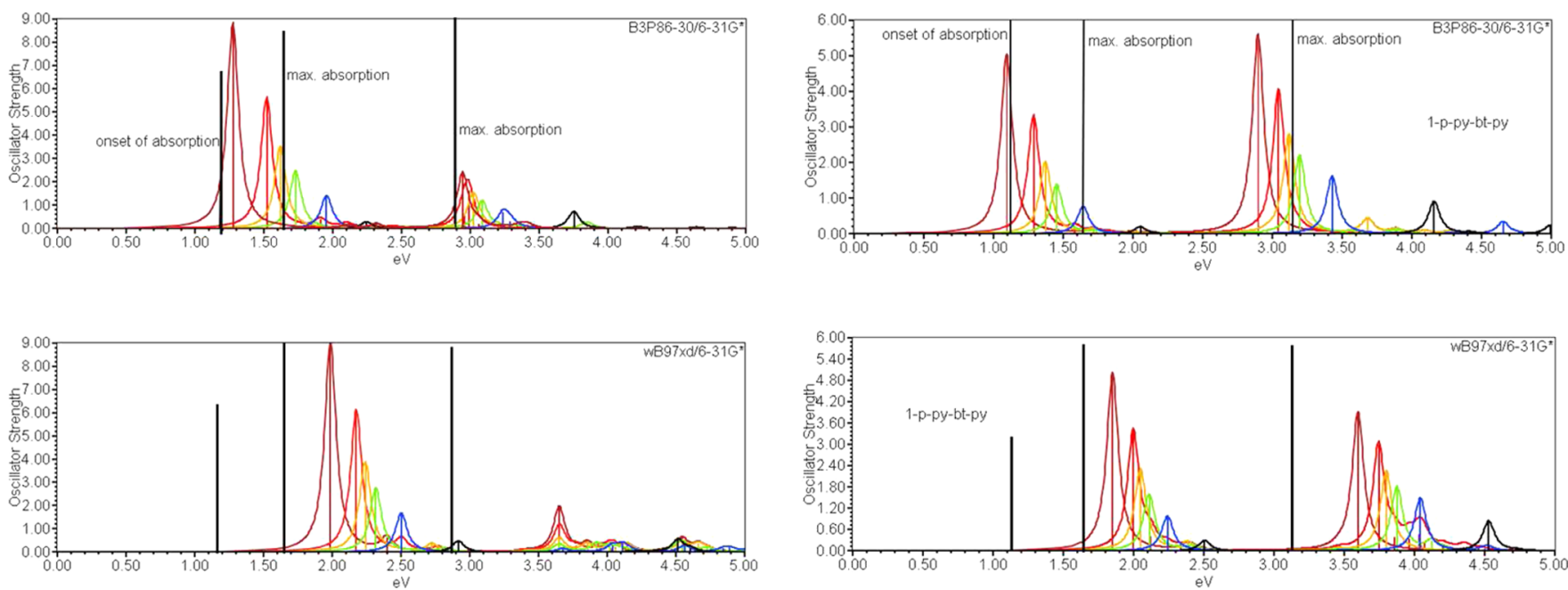

Figure 2. Monomer (black) through hexamers (red) and extrapolated polymer (brown) spectra of EDOT-BT-EDOT (left) and PY-BT-PY (right) at B3P86-30\%/6-31G* and wB97XD/6-31G*. Black bars show experimental values on thin films.

Table 1. HOMO (Top) and LUMO (Bottom) Energies of Donors and Acceptors and HOMO and LUMO Energy Differences between Donors and Acceptors (In Italics) at wB97XD/6-31G* in Electronvolts $(\mathrm{eV})^{a}$

\begin{tabular}{cllll} 
donor-acceptor & & TH & EDOT & \multicolumn{1}{c}{ PY } \\
& HOMO & -8.46 & -7.83 & -7.58 \\
& LUMO & 1.76 & 1.88 & 3.45 \\
FTH & -8.87 & -0.41 & -1.04 & $-\mathbf{1 . 2 9}$ \\
& 1.34 & -0.42 & -0.54 & -2.11 \\
PYPY & -7.68 & $\mathbf{0 . 7 8}$ & $\mathbf{0 . 1 5}$ & $-\mathbf{0 . 1 0}$ \\
& -0.49 & -2.25 & -2.37 & -3.94 \\
BT & -8.63 & -0.17 & -0.80 & -1.05 \\
& -0.54 & -2.30 & -2.42 & -3.99 \\
CDM & -8.07 & $\mathbf{0 . 3 9}$ & -0.24 & -0.59 \\
& -1.76 & -3.52 & -3.64 & -5.21 \\
IFDMT & -8.39 & $\mathbf{0 . 0 7}$ & -0.56 & -0.81 \\
& -2.37 & -4.12 & -4.25 & -5.82
\end{tabular}

${ }^{a}$ Entries for donor-acceptor systems investigated in this study are given in bold face.

Table 2. Orbital and Excitation Energies (Oscillator Strengths in Parentheses) of PY-FTH-PY Oligomers in Electronvolts $(\mathrm{eV})$, with B3P86-30\% and with wB97XD below in Italics ${ }^{a}$

$\begin{array}{cclccc}\text { PY-FTH-PY } & E_{\text {НОмо }} & E_{\text {LUMO }} & E_{\mathrm{g}} & \text { exc } 1 & \\ \text { monomer } & -5.85 & -1.55 & 4.30 & 3.63(0.89) & 1-1^{\prime}(0.89) \\ & -6.71 & 0.53 & 7.24 & 3.86(0.88) & 1-1^{\prime}(0.70) \\ \text { dimer } & -5.49 & -1.89 & 3.60 & 2.91(2.08) & 1-1^{\prime}(0.70) \\ & -6.30 & 0.19 & 6.49 & 3.35(2.24) & 1-1^{\prime}(0.63) \\ \text { trimer } & -5.38 & -2.03 & 3.35 & 2.65(3.16) & 1-1^{\prime}(0.68) \\ & -6.20 & 0.05 & 6.24 & 3.16(3.47) & 1-1^{\prime}(0.59) \\ \text { tetramer } & -5.35 & -2.10 & 3.25 & 2.53(4.32) & 1-1^{\prime}(0.65) \\ & -6.16 & -0.02 & 6.13 & 3.07(4.74) & 1-1^{\prime}(0.54) \\ \text { polymer } & -5.24 & -2.34 & 2.89 & 2.14 & \\ & -6.05 & -0.26 & 5.79 & 2.77 & \end{array}$

${ }^{a}$ Polymer values are obtained by extrapolation with 2 nd degree polynomial fits.

Properties of Donor-Acceptor Systems. In Tables 2-12, orbital energies, HOMO-LUMO gaps, and TDDFT excitation energies for monomers through tetramers (in some cases up to hexamers) are collected. Experimental values are included where
Table 3. Orbital and Excitation Energies (Oscillator Strengths in Parentheses) of TH-PYPY-TH Oligomers in Electronvolts $(\mathrm{eV})$, with B3P86-30\% and with wB97XD below in Italics ${ }^{a}$

\begin{tabular}{llllll}
$\begin{array}{l}\text { TH-PYPY- } \\
\text { TH }\end{array}$ & $E_{\text {HOMO }}$ & $E_{\text {LUMO }}$ & $E_{\mathrm{g}}$ & \multicolumn{1}{c}{ exc 1} & \\
monomer & -5.99 & -2.92 & 3.06 & $2.55(0.52)$ & $1-1^{\prime}(0.60)$ \\
& -6.79 & -0.93 & 5.86 & $2.74(0.52)$ & $1-1^{\prime}(0.70)$ \\
expt. & & & & 2.25 & \\
dimer & -5.82 & -3.42 & 2.40 & $1.96(1.86)$ & $1-1^{\prime}(0.70)$ \\
& -6.62 & -1.41 & 5.20 & $2.39(1.79)$ & $1-1^{\prime}(0.62)$ \\
trimer & -5.76 & -3.61 & 2.15 & $1.69(3.14)$ & $1-1^{\prime}(0.69)$ \\
& -6.53 & -1.64 & 4.90 & $2.18(3.08)$ & $1-1^{\prime}(0.58)$ \\
tetramer & -5.73 & -3.70 & 2.03 & $1.56(4.32)$ & $1-1^{\prime}(0.68)$ \\
& -6.51 & -1.73 & 4.78 & $2.10(4.33)$ & $1-1^{\prime}(0.54)$ \\
pentamer & -5.72 & -3.75 & 1.97 & $1.48(5.58)$ & $1-1^{\prime}(0.66)$ \\
hexamer & -5.71 & -3.78 & 1.93 & $1.44(6.79)$ & $1-1^{\prime}(0.63)$ \\
& -6.49 & -1.81 & 4.68 & $2.03(6.80)$ & $1-1^{\prime}(0.46)$ \\
polymer & -5.65 & -3.97 & 1.68 & 1.14 & \\
& -6.42 & -2.04 & 4.38 & 1.80 & \\
expt. ${ }^{95}$ & & & & 1.38 &
\end{tabular}

${ }^{a}$ Polymer values are obtained by extrapolation with 2 nd degree polynomial fits.

Table 4. Orbital and Excitation Energies (Oscillator Strengths in Parentheses) of EDOT-PYPY-EDOT Oligomers in Electronvolts (eV), with B3P86-30\% and with wB97XD below in Italics ${ }^{a}$

\begin{tabular}{|c|c|c|c|c|c|}
\hline $\begin{array}{l}\text { EDOT-PYPY- } \\
\text { EDOT }\end{array}$ & $E_{\text {номо }}$ & $E_{\text {LUMO }}$ & $E_{\mathrm{g}}$ & exc 1 & \\
\hline \multirow[t]{2}{*}{ monomer } & -5.73 & -2.63 & 3.10 & $2.61(0.67)$ & $1-1^{\prime}(0.61)$ \\
\hline & -6.51 & -0.65 & 5.86 & $2.80(0.57)$ & $1-1^{\prime}(0.70)$ \\
\hline \multirow[t]{2}{*}{ dimer } & -5.42 & -3.00 & 2.42 & $1.97(1.83)$ & $1-1^{\prime}(0.70)$ \\
\hline & -6.17 & -1.03 & 5.14 & $2.36(1.52)$ & $1-1^{\prime}(0.63)$ \\
\hline \multirow[t]{2}{*}{ trimer } & -5.30 & -3.12 & 2.18 & $1.70(2.98)$ & $1-1^{\prime}(0.69)$ \\
\hline & -6.03 & -1.16 & 4.87 & $2.18(2.45)$ & $1-1^{\prime}(0.59)$ \\
\hline \multirow[t]{2}{*}{ tetramer } & -5.23 & -3.18 & 2.05 & $1.57(4.11)$ & $1-1^{\prime}(0.67)$ \\
\hline & -5.97 & -1.22 & 4.75 & $2.10(3.44)$ & $1-1^{\prime}(0.55)$ \\
\hline \multirow[t]{2}{*}{ polymer } & -5.01 & -3.36 & -1.66 & 1.11 & \\
\hline & -5.76 & -1.40 & 4.36 & 1.79 & \\
\hline
\end{tabular}

${ }^{a}$ Polymer values are obtained by extrapolation with 2 nd degree polynomial fits. 
Table 5. Orbital and Excitation Energies (Oscillator Strengths in Parentheses) of PY-PYPY-PY Oligomers in Electronvolts $(\mathrm{eV})$, with B3P86-30\% and with wB97XD below in Italics ${ }^{a}$

\begin{tabular}{|cccccc}
$\begin{array}{c}\text { PY-PYPY- } \\
\text { PY }\end{array}$ & $E_{\text {HOMO }}$ & $E_{\text {LUMO }}$ & $E_{\mathrm{g}}$ & exc 1 & \\
\hline monomer & -5.77 & -2.60 & 3.17 & $2.69(0.57)$ & $1-1^{\prime}(0.60)$ \\
& -6.56 & -0.66 & 5.91 & $2.82(0.67)$ & $1-1^{\prime}(0.70)$ \\
dimer & -5.51 & -2.89 & 2.62 & $2.11(1.48)$ & $1-1^{\prime}(0.70)$ \\
& -6.24 & -0.96 & 5.28 & $2.43(1.81)$ & $1-1^{\prime}(0.63)$ \\
trimer & -5.41 & -3.01 & 2.40 & $1.87(2.40)$ & $1-1^{\prime}(0.69)$ \\
& -6.12 & -1.08 & 5.04 & $2.26(2.93)$ & $1-1^{\prime}(0.59)$ \\
tetramer & -5.36 & -3.07 & 2.29 & $1.75(3.33)$ & $1-1^{\prime}(0.67)$ \\
& -6.07 & -1.14 & 4.94 & $2.17(4.07)$ & $1-1^{\prime}(0.55)$ \\
polymer & -5.24 & -3.22 & 2.02 & 1.46 & \\
& -5.96 & -1.29 & 4.71 & 1.94 &
\end{tabular}

${ }^{a}$ Polymer values are obtained by extrapolation with 2 nd degree polynomial fits.

available. Table 13 summarizes differences between monomer and polymer values. Large differences between monomer and polymer indicate strong conjugation along the backbone.

The highest excitation energy of any monomer is computed for PT-FTH-PY, and the values decrease in parallel with the EA of the acceptor (Table 1) with one exception: the first excitation energy of TH-IFDMT-TH is larger than that of TH-CDM-TH, although IFDMT has the highest EA of all acceptors. The smallest final polymer band gaps (Tables 2-12) are those of p-EDOTCDM-EDOT and p-PY-CDM-PY $(0.94 \mathrm{eV})$ followed by p-PYBT-PY $(1.10 \mathrm{eV})$, p-EDOT-PYPY-EDOT $(1.11 \mathrm{eV})$, and p-THPYPY-TH $(1.14 \mathrm{eV})$. Interestingly, PY, which gives the smallest band gap of the three donors with BT and CDM, leads to the largest band gap with PYPY $(1.46 \mathrm{eV})$, and $\mathrm{TH}$, which gives the largest band gap with CDM and IFTMD, leads to a very small band gap $(1.14 \mathrm{eV})$ with PYPY. Thus, any of the three acceptors, PYPY, BT, and CDM can produce a small band gap polymer when combined with the right donor. Attempts to correlate the band gaps with relative orbital energies of donors and acceptors were unsuccessful.

On chain length increase, the decrease in first excitation energy (Table 13) ranges from 1.50 to $0.24 \mathrm{eV}$ with $\mathrm{B} 3 \mathrm{P} 86-30 \%$ and form 1.09 to 0.06 with $w B 97 X D$. The decrease in HOMOLUMO gaps $\left(E_{\mathrm{g}}\right)$ is almost the same with the two functionals, between 1.5 and $0.58 \mathrm{eV}$. The largest values are predicted for PYFTH-PY and PYPY systems. BT oligomers have slightly reduced chain length dependence and the smallest band gap reductions are found with CDM and IFDMT. Trends in HOMO-LUMO gaps parallel those of the first excitation energy, but the individual chain lengths dependencies of HOMOs and LUMOs vary

Table 6. Orbital and Excitation Energies in eV, Oscillator Strengths (In Parentheses), Dominant Electronic Transition with Its CI Coefficient (In Parentheses) of TH-BT-TH oligomers, with B3P86-30\% and with wB97XD below in Italics ${ }^{a}$

\begin{tabular}{|c|c|c|c|c|c|c|c|}
\hline \multirow{2}{*}{$\begin{array}{l}\text { TH-BT-TH } \\
\text { monomer }\end{array}$} & \multirow{2}{*}{$\begin{array}{c}E_{\text {Номо }} \\
-6.39\end{array}$} & \multirow{2}{*}{$\begin{array}{r}E_{\mathrm{LUMO}} \\
-3.00\end{array}$} & \multirow{2}{*}{$\begin{array}{c}E_{\mathrm{g}} \\
3.40\end{array}$} & \multicolumn{2}{|c|}{ exc 1} & \multicolumn{2}{|r|}{ exc 2} \\
\hline & & & & $2.63(0.35)$ & $1-1^{\prime}(0.89)$ & $4.18(0.43)$ & $1-2^{\prime}(0.56)$ \\
\hline & -7.24 & -0.96 & 6.27 & $3.01(0.44)$ & $1-1^{\prime}(0.70)$ & $4.57(0.45)$ & $1-2^{\prime}(0.65)$ \\
\hline expt. $^{96}$ & & & & 2.77 & & & \\
\hline dimer & -6.00 & -3.24 & 2.77 & $2.14(1.41)$ & $1-1^{\prime}(0.69)$ & $3.34(0.75)$ & $1-3^{\prime}(0.68)$ \\
\hline & -6.80 & -1.22 & 5.58 & $2.65(1.64)$ & $1-1^{\prime}(0.62)$ & $4.28(0.39)$ & $1-3^{\prime} / 3-1^{\prime}(0.41 /-0.38)$ \\
\hline expt. $^{96}$ & & & & 2.38 & & & \\
\hline trimer & -5.89 & -3.35 & 2.54 & $1.93(2.40)$ & $1-1^{\prime}(0.68)$ & $3.20(0.92)$ & $1-4^{\prime}(0.65)$ \\
\hline & -6.68 & -1.27 & 5.51 & $2.61(2.47)$ & $1-1^{\prime}(0.58)$ & $3.86(0.48)$ & $1-4^{\prime}(0.46)$ \\
\hline tetramer & -5.85 & -3.41 & 2.44 & $1.82(3.41)$ & $1-1^{\prime}(0.65)$ & $3.16(1.20)$ & $1-5^{\prime}(0.60)$ \\
\hline & -6.73 & -1.32 & 5.41 & $2.54(3.56)$ & $1-1^{\prime}(0.53)$ & $3.85(0.82)$ & $1-5^{\prime}(0.41)$ \\
\hline polymer & -5.71 & -3.62 & 2.09 & 1.45 & & 3.13 & \\
\hline & -6.58 & -1.53 & 5.05 & 2.26 & & 3.85 & \\
\hline
\end{tabular}

${ }^{a}$ Polymer values are obtained by extrapolation with 2 nd degree polynomial fits.

Table 7. Orbital and Excitation Energies in Electronvolts (eV), Oscillator Strengths (In Parentheses), Dominant Electronic Transition with Its CI Coefficient (In Parentheses) of EDOT-BT-EDOT Oligomers, with B3P86-30\% and with wB97XD below in Italics $^{a}$

\begin{tabular}{|c|c|c|c|c|c|c|c|}
\hline \multirow{2}{*}{$\begin{array}{l}\text { EDOT-BT-EDOT } \\
\text { monomer }\end{array}$} & \multirow{2}{*}{$\begin{array}{c}E_{\text {Номо }} \\
-5.93\end{array}$} & \multirow{2}{*}{$\begin{array}{r}E_{\text {LUMO }} \\
-2.68\end{array}$} & \multirow{2}{*}{$\begin{array}{c}E_{\mathrm{g}} \\
3.25\end{array}$} & \multicolumn{2}{|c|}{ exc 1} & \multicolumn{2}{|c|}{$\operatorname{exc} 2$} \\
\hline & & & & $2.50(0.37)$ & $1-1^{\prime}(0.70)$ & $4.05(0.70)$ & $1-2^{\prime}(0.70)$ \\
\hline \multirow{3}{*}{ dimer } & -6.77 & -0.64 & 6.13 & $2.92(0.49)$ & $1-1^{\prime}(0.70)$ & $4.51(0.54)$ & $1-2^{\prime}(0.67)$ \\
\hline & -5.36 & -2.82 & 2.55 & $1.96(1.42)$ & $1-1^{\prime}(0.69)$ & $3.24(0.69)$ & $1-3^{\prime}(0.54)$ \\
\hline & -6.14 & -0.80 & 5.34 & $2.51(1.69)$ & $1-1^{\prime}(0.63)$ & $3.67(0.15)$ & $1-3^{\prime}(0.43)$ \\
\hline \multirow[t]{2}{*}{ trimer } & -5.18 & -2.88 & 2.30 & $1.73(2.48)$ & $1-1^{\prime}(0.68)$ & $3.09(1.20)$ & $1-4^{\prime}(0.66)$ \\
\hline & -5.94 & -0.87 & 5.07 & $2.32(2.78)$ & $1-1^{\prime}(0.59)$ & $3.65(0.33)$ & $1-4^{\prime}(0.43)$ \\
\hline \multirow[t]{2}{*}{ tetramer } & -5.10 & -2.91 & 2.19 & $1.62(3.54)$ & $1-1^{\prime}(0.66)$ & $3.02(1.43)$ & $1-5^{\prime}(0.58)$ \\
\hline & -5.86 & -0.90 & 4.96 & $2.24(3.91)$ & $1-1^{\prime}(0.54)$ & $3.65(0.60)$ & $1-5^{\prime}(0.40)$ \\
\hline \multirow[t]{2}{*}{ hexamer } & -5.02 & -2.93 & 2.09 & $1.52(5.65)$ & $1-1^{\prime}(0.61)$ & $2.99(1.61)$ & $1-7^{\prime}(0.49)$ \\
\hline & -5.79 & -0.93 & 4.87 & $2.18(6.14)$ & $1-1^{\prime}(0.47)$ & $3.65(1.15)$ & $1-6^{\prime}(0.33)$ \\
\hline \multirow[t]{2}{*}{ polymer } & -4.86 & -3.00 & 1.86 & 1.28 & & 2.95 & \\
\hline & -5.64 & -1.00 & 4.64 & 1.99 & & 3.65 & \\
\hline expt. $^{78}$ & & & & 1.64 & & 2.90 & \\
\hline
\end{tabular}

${ }^{a}$ Polymer values are obtained by extrapolation with 2 nd degree polynomial fits. 
Table 8. Orbital and Excitation Energies in Electronvolts (eV), Oscillator Strengths (In Parentheses), Dominant Electronic Transition with its CI Coefficient (In Parentheses) of PY-BT-PY Oligomers, with B3P86-30\% and with wB97XD below in Italics ${ }^{a}$

$\begin{array}{lcccl}\text { PY-BT-PY } & E_{\text {HOMO }} & E_{\text {LUMO }} & E_{\mathrm{g}} & \\ \text { monomer } & -5.77 & -2.94 & 2.83 & 2.06(0.21) \\ & -6.60 & -0.92 & 5.68 & 2.51(0.30) \\ \text { expt. }^{96} & & & & 2.33 \\ \text { dimer } & -5.30 & -3.06 & 2.24 & 1.64(0.78) \\ \text { trimer } & -6.10 & -1.04 & 5.06 & 2.24(0.99) \\ & -5.16 & -3.12 & 2.04 & 1.46(1.39) \\ \text { tetramer } & -5.96 & -1.10 & 4.86 & 2.11(1.61) \\ & -5.10 & -3.15 & 1.95 & 1.38(2.04) \\ \text { hexamer } & -5.90 & -1.13 & 4.77 & 2.05(2.32) \\ & -5.05 & -3.18 & 1.87 & 1.29(3.34) \\ \text { polymer }^{*} & -5.85 & -1.18 & 4.69 & 2.00(3.38) \\ \text { expt. }^{78} & -4.93 & -3.26 & 1.68 & 1.10 \\ & -5.75 & -1.23 & 4.52 & 1.85\end{array}$

exc 1

(1)

$\operatorname{exc} 2$

$\begin{array}{lll}1-1^{\prime}(0.70) & 4.16(0.70) & 1-2^{\prime}(0.70) \\ 1-1^{\prime}(0.70) & 4.53(0.80) & 1-2^{\prime}(0.68)\end{array}$

$1-1^{\prime}(0.69)$

$4.42(1.64) \quad 1-3^{\prime}(0.69)$

$4.04(1.50) \quad 1-3^{\prime}(0.61)$

$3.20(2.21) \quad 1-4^{\prime}(0.67)$

$1-1^{\prime}(0.68)$

$1-1^{\prime}(0.59)$

$1-1^{\prime}(0.65)$

$1-1^{\prime}(0.54)$

3.88 (1.82)

$1-4^{\prime}(0.52)$

$3.12(2.80)$

$1-5^{\prime}(0.64)$

$1-5^{\prime}(0.46)$

$1-1^{\prime}(0.61) \quad 3.05(4.05) \quad 1-7^{\prime}(0.58)$

$1-1^{\prime}(0.47) \quad 3.75(2.99) \quad 1-7^{\prime}(0.40)$

2.90

3.60

3.16

${ }^{a}$ Polymer values are obtained by extrapolation with 2 nd degree polynomial fits.

Table 9. Orbital and Excitation Energies in Electronvolts (eV), Oscillator Strengths (In Parentheses), Dominant Electronic Transition with Its CI Coefficient (In Parentheses) of TH-CDM-TH Oligomers, with B3P86-30\% and with wB97XD below in Italics $^{a}$

\begin{tabular}{|c|c|c|c|c|c|c|c|}
\hline \multirow{2}{*}{$\begin{array}{c}\text { TH-CDM-TH } \\
\text { monomer }\end{array}$} & \multirow{2}{*}{$\begin{array}{c}E_{\text {Номо }} \\
-6.41\end{array}$} & \multirow{2}{*}{$\begin{array}{r}E_{\text {LUMO }} \\
-3.86\end{array}$} & \multirow{2}{*}{$\begin{array}{c}E_{\mathrm{g}} \\
2.55\end{array}$} & \multicolumn{2}{|c|}{ exc 1} & \multicolumn{2}{|c|}{ exc 2} \\
\hline & & & & $1.49(0.05)$ & $1-1^{\prime}(0.70)$ & $3.48(0.82)$ & $1-2^{\prime}(0.67)$ \\
\hline & -7.34 & -1.79 & 5.55 & $1.95(0.06)$ & $1-1^{\prime}(0.68)$ & $4.03(0.99)$ & $1-2^{\prime}(0.65)$ \\
\hline \multirow{2}{*}{ dimer } & -6.16 & -3.95 & 2.21 & $1.37(0.22)$ & $1-1^{\prime}(0.61)$ & $2.73(2.18)$ & $1-3^{\prime}(0.65)$ \\
\hline & -7.07 & -1.89 & 5.18 & $1.91(0.21)$ & $1-1^{\prime}(0.49)$ & $3.34(2.21)$ & $1-3^{\prime}(0.54)$ \\
\hline \multirow[t]{2}{*}{ trimer } & -6.11 & -4.02 & 2.09 & $1.29(0.32)$ & $1-1^{\prime}(0.64)$ & $2.58(3.8)$ & $1-4^{\prime}(0.64)$ \\
\hline & -7.03 & -1.95 & & $1.89(0.32)$ & $1-1^{\prime}(0.51)$ & $3.25(4.08)$ & $1-4^{\prime}(0.50)$ \\
\hline \multirow[t]{2}{*}{ tetramer } & -6.06 & -4.04 & 2.02 & $1.26(0.60)$ & $1-1^{\prime}(0.57)$ & $2.47 / 2.49(2.95 / 1.99)$ & $1-5^{\prime}(0.44 / 0.39)$ \\
\hline & -7.01 & -1.97 & 5.04 & $1.88(0.49)$ & $1-1^{\prime}(0.45)$ & $3.22(5.62)$ & $1-5^{\prime}(0.46)$ \\
\hline \multirow[t]{2}{*}{ polymer } & -6.00 & -4.16 & 1.84 & 1.12 & & 2.31 & \\
\hline & -7.00 & -2.07 & 4.93 & 1.85 & & 3.17 & \\
\hline
\end{tabular}

${ }^{a}$ Polymer values are obtained by extrapolation with 2 nd degree polynomial fits.

Table 10. Orbital and Excitation Energies in Electronvolts (eV), Oscillator Strengths (In Parentheses), Dominant Electronic Transition with Its CI Coefficient (In Parentheses) of EDOT-CDM-EDOT Oligomers, with B3P86-30\% and with wB97XD below in Italics ${ }^{a}$

\begin{tabular}{|c|c|c|c|c|c|c|c|}
\hline \multirow{2}{*}{$\begin{array}{c}\text { EDOT-CDM-EDOT } \\
\text { monomer }\end{array}$} & \multirow{2}{*}{$\begin{array}{c}E_{\text {номо }} \\
-5.95\end{array}$} & \multirow{2}{*}{$\begin{array}{l}E_{\text {LUMO }} \\
-3.57\end{array}$} & \multirow{2}{*}{$\begin{array}{c}E_{\mathrm{g}} \\
2.38\end{array}$} & \multicolumn{2}{|c|}{ exc 1} & \multicolumn{2}{|c|}{$\operatorname{exc} 2$} \\
\hline & & & & $1.35(0.05)$ & $1-1^{\prime}(0.70)$ & $3.27(1.08)$ & $1-2^{\prime}(0.69)$ \\
\hline & -6.80 & -1.52 & 5.28 & $1.79(0.06)$ & $1-1^{\prime}(0.68)$ & $3.72(1.22)$ & $1-2^{\prime}(0.66)$ \\
\hline expt. $^{64}$ & & & & 1.51 & & 3.44 & \\
\hline \multirow[t]{2}{*}{ dimer } & -5.57 & -3.61 & 1.95 & $1.17(0.24)$ & $1-1^{\prime}(0.63)$ & $2.50(2.52)$ & $1-3^{\prime}(0.68)$ \\
\hline & -6.36 & -1.57 & 4.80 & $1.70(0.26)$ & $1-1^{\prime}(0.51)$ & $2.96(2.28)$ & $1-3^{\prime}(0.57)$ \\
\hline \multirow[t]{2}{*}{ trimer } & -5.46 & -3.64 & 1.82 & $1.07(0.33)$ & $1-1^{\prime}(0.61)$ & $2.31(3.97)$ & $1-4^{\prime}(0.66)$ \\
\hline & -6.25 & -1.59 & 4.67 & $1.65(0.39)$ & $1-1^{\prime}(0.50)$ & $2.86(4.14)$ & $1-4^{\prime}(0.52)$ \\
\hline \multirow[t]{2}{*}{ tetramer } & -5.42 & -3.65 & 1.77 & $1.04(0.60)$ & $1-1^{\prime}(0.58)$ & $2.20 / 2.25(2.61 / 2.47)$ & $1-5^{\prime}(0.39 / 0.43)$ \\
\hline & -6.21 & -1.60 & 4.61 & $1.64(0.63)$ & $1-1^{\prime}(0.45)$ & $2.81(5.80)$ & $1-5^{\prime}(0.47)$ \\
\hline \multirow[t]{2}{*}{ polymer } & -5.27 & -3.67 & 1.61 & 0.94 & & 1.85 & \\
\hline & -6.10 & -1.63 & 4.46 & 1.55 & & 2.74 & \\
\hline expt. $^{64}$ & & & & 0.95 & & 2.27 & \\
\hline
\end{tabular}

${ }^{a}$ Polymer values are obtained by extrapolation with 2 nd degree polynomial fits.

considerably. The largest differences between monomer and polymer are computed for the IP (HOMO) of EDOT-BT-EDOT $(1.07 \mathrm{eV})$ and for the EA (LUMO) of TH-PYPY-TH $(1.01 \mathrm{eV})$. With PYPY, the decrease in the band gaps is dominated by the increase in the EAs. This is indicative of significant delocalization of the conduction band and predicts high electron mobility in diketopyrrolopyrrole systems. With BT it is the IP that makes the main contribution. Thus, BT is a p-type material. The much smaller EA decrease from monomer to polymer of BT compared to PYPY systems cannot be explained by different EAs because both acceptors have almost the same EA (Table 1). With CDM and IFTMD chain length dependencies of IPs and EAs are significantly less than with the other acceptors. In particular, the EAs increase only by $0.1-0.28 \mathrm{eV}$ from monomer to polymer. 
Table 11. Orbital and Excitation Energies in Electronvolts (eV), Oscillator Strengths (In Parentheses), Dominant Electronic Transition with Its CI Coefficient (In Parentheses) of EDOT-CDM-EDOT Oligomers, with B3P86-30\% and with wB97XD below in Italics ${ }^{a}$

\begin{tabular}{|c|c|c|c|c|c|c|c|}
\hline \multirow{2}{*}{$\begin{array}{c}\text { PY-CDM-PY } \\
\text { monomer }\end{array}$} & \multirow{2}{*}{$\begin{array}{c}E_{\mathrm{HOMO}} \\
-6.03\end{array}$} & \multirow{2}{*}{$\begin{array}{l}E_{\text {LUMO }} \\
-3.77\end{array}$} & \multirow{2}{*}{$\begin{array}{c}E_{\mathrm{g}} \\
2.26\end{array}$} & \multicolumn{2}{|c|}{ exc 1} & \multicolumn{2}{|c|}{$\operatorname{exc} 2$} \\
\hline & & & & $1.25(0.04)$ & $1-1^{\prime}(0.70)$ & $3.58(0.80)$ & $1-2^{\prime}(0.64)$ \\
\hline & -6.93 & -1.73 & 5.20 & $1.74(0.05)$ & $1-1^{\prime}(0.67)$ & $4.02 / 4.03(0.56 / 0.69)$ & $3-1^{\prime} / 7-1^{\prime}(0.65 / 0.42)$ \\
\hline \multirow[t]{2}{*}{ dimer } & -5.71 & -3.84 & 1.87 & $1.09(0.16)$ & $1-1^{\prime}(0.64)$ & $2.92(2.47)$ & $1-3^{\prime}(0.63)$ \\
\hline & -6.57 & -1.80 & 4.77 & $1.70(0.17)$ & $1-1^{\prime}(0.49)$ & $3.53(2.66)$ & $1-3^{\prime}(0.57)$ \\
\hline \multirow[t]{2}{*}{ trimer } & -5.69 & -3.89 & 1.80 & $1.03(0.20)$ & $1-1^{\prime}(0.65)$ & $2.81(3.47)$ & $1-4^{\prime}(0.58)$ \\
\hline & -6.56 & -1.86 & 4.70 & $1.69(0.25)$ & $1-1^{\prime}(0.50)$ & $3.43(3.22)$ & $1-4^{\prime}(0.41)$ \\
\hline \multirow[t]{2}{*}{ tetramer } & -5.67 & -3.91 & 1.76 & $1.01(0.34)$ & $1-1^{\prime}(0.59)$ & $2.75(5.01)$ & $1-5^{\prime}(0.57)$ \\
\hline & -6.54 & -1.87 & 4.67 & $1.68(0.36)$ & $1-1^{\prime}(0.43)$ & $3.38 / 3.65(4.75 / 1.21)$ & $1-5^{\prime} / 1-1^{\prime}(0.47 / 0.35)$ \\
\hline \multirow[t]{2}{*}{ polymer } & -5.65 & -4.01 & 1.64 & 0.94 & & 2.69 & \\
\hline & -6.52 & -1.96 & 4.56 & 1.66 & & 3.29 & \\
\hline
\end{tabular}

${ }^{a}$ Polymer values are obtained by extrapolation with 2 nd degree polynomial fits.

Table 12. Orbital and Excitation Energies in Electronvolts (eV), Oscillator Strengths (In Parentheses), Dominant Electronic Transition with Its CI Coefficient (In Parentheses) of TH-IFDMT-TH Oligomers, with B3P86-30\% and with wB97XD below in Italics $^{a}$

\begin{tabular}{|c|c|c|c|c|c|c|c|}
\hline TH-IFDMT-TH & $E_{\text {НОмо }}$ & $E_{\text {LUMO }}$ & $E_{\mathrm{g}}$ & \multicolumn{2}{|c|}{ exc 1} & \multicolumn{2}{|c|}{ exc 2} \\
\hline \multirow[t]{2}{*}{ monomer } & -6.91 & -4.40 & 2.50 & $1.65(0.03)$ & $1-1^{\prime}(0.69)$ & $3.72(1.94)$ & $3-1^{\prime}(-0.47)$ \\
\hline & -7.76 & -2.39 & 5.37 & $2.27(0.03)$ & $1-1^{\prime}(0.64)$ & $4.02 / 4.30(1.36 / 1.50)$ & $1-4^{\prime}(0.43 / 0.35)$ \\
\hline expt. $^{97}$ & & & & 1.89 & & 2.96 & \\
\hline \multirow[t]{2}{*}{ dimer } & -6.58 & -4.46 & 2.11 & $1.49(0.16)$ & $1-1^{\prime}(0.64)$ & $2.92(2.03)$ & $1-5^{\prime}(0.52)$ \\
\hline & -7.40 & -2.41 & 4.98 & $2.25(0.14)$ & $1-1^{\prime}(0.43)$ & $3.48(2.87)$ & $1-5^{\prime}(0.46)$ \\
\hline \multirow[t]{2}{*}{ trimer } & -6.54 & -4.51 & 2.04 & $1.42(0.18)$ & $1-1^{\prime}(0.66)$ & $2.85(4.00)$ & $1-8^{\prime}(0.55)$ \\
\hline & -7.37 & -2.49 & 4.88 & $2.24(0.21)$ & $1-1^{\prime}(0.47)$ & $3.39(5.27)$ & $1-7^{\prime}(0.40)$ \\
\hline \multirow[t]{2}{*}{ tetramer } & -6.53 & -4.52 & 2.01 & $1.42(0.33)$ & $1-1^{\prime}(0.58)$ & $2.83(5.30)$ & $1-9^{\prime}(0.51)$ \\
\hline & -7.37 & -2.50 & 4.87 & $2.23(0.34)$ & $1-1^{\prime}(0.41)$ & $3.36(7.54)$ & $1-9^{\prime}(0.35)$ \\
\hline \multirow[t]{2}{*}{ polymer } & -6.51 & -4.60 & 1.91 & 1.41 & & 2.93 & \\
\hline & -7.37 & -2.58 & 4.79 & 2.21 & & 3.34 & \\
\hline expt. $^{97}$ & & & & 1.82 & & 2.66 & \\
\hline
\end{tabular}

${ }^{a}$ Polymer values are obtained by extrapolation with 2 nd degree polynomial fits.

UV Spectra. UV spectra of monomers through tetramers in Figure 3 reveal that the donor-acceptor systems studied here fall into three groups. With FTH and PYPY as acceptors, one strong absorption is predicted and there is a large $(1.23-1.50 \mathrm{eV})$ bathochromic shift accompanied by increasing oscillator strength with increasing oligomer length. With BT, two absorptions are seen and the oscillator strength shifts from the low energy to the high energy band with increasing donor strength in the order $\mathrm{TH}<\mathrm{EDOT}<\mathrm{PY}$. The bathochromic shift upon chain increase is reduced to $0.96-1.22 \mathrm{eV}$ (Table 13). With CDM and IFDMT, there is a only a very weak feature at low energy that shifts by 0.24-0.41 eV with increasing chain length and almost all of the oscillator strength is found in the high energy band with any donor.

The different spectra of PYPY and BT systems cannot be explained with different acceptor strength in terms of orbital energies because PYPY and BT have almost the same EA (Table 1). Orbital energy plots of tetramers in Figure 4 show that the gradual shift in oscillator strength from the first to a second absorption occurs in parallel with decreasing level spacing of the first four unoccupied energy levels which is in turn paralleled with the reduced chain length dependence of the EAs (Tables 2-12). All these observations are in line with excitation from the valence band into increasingly localized conduction band states.

It is noteworthy that the oscillator strengths in systems with the dual band absorptions are always weaker than those of
Table 13. Differences between Monomer and Polymers Properties of Donor-Acceptor Systems, Top at B3P86-30\%/6-31G*, Bottom in Italics wB97XD/6-31G*

\begin{tabular}{llllll}
\multicolumn{1}{c}{$\Delta_{\text {mon-pol }}$} & $E_{\text {HOMO }}$ & $E_{\text {LUMO }}$ & $E_{\mathrm{g}}$ & exc 1 & exc 2 \\
PY-FTH-PY & -0.61 & 0.79 & -1.41 & -1.49 & \\
& -0.66 & 0.79 & -1.45 & -0.99 & \\
TH-PYPY-TH & -0.34 & 1.05 & -1.38 & -1.46 & \\
EDOT-PYPY-EDOT & -0.37 & 1.01 & -1.48 & -1.09 & \\
& -0.71 & -0.73 & -1.44 & -1.50 & \\
PY-PYPY-PY & -0.75 & -0.75 & -1.50 & -1.01 & \\
& -0.53 & 0.62 & -1.15 & -1.23 & \\
TH-BT-TH & -0.40 & 0.63 & -1.20 & -0.88 & \\
& -0.68 & 0.62 & -1.31 & -1.18 & -1.05 \\
EDOT-BT-EDOT & -0.66 & 0.57 & -1.22 & -0.75 & -0.72 \\
& -1.07 & 0.32 & -1.39 & -1.22 & -1.10 \\
PY-BT-PY & -1.13 & 0.36 & -1.49 & -0.93 & -0.86 \\
& -0.84 & 0.32 & -1.15 & -0.96 & -1.26 \\
TH-CDM-TH & -0.85 & 0.31 & -1.16 & -0.66 & -0.93 \\
& -0.41 & 0.10 & -0.71 & -0.37 & -1.17 \\
EDOT-CDM-EDOT & -0.34 & 0.28 & -0.63 & -0.10 & -0.85 \\
& -0.68 & 0.10 & -0.77 & -0.41 & -1.42 \\
PY-CDM-PY & -0.70 & 0.11 & -0.82 & -0.24 & -0.98 \\
& -0.38 & 0.24 & -0.64 & -0.31 & -0.89 \\
TH-IFDMT-TH & -0.41 & 0.23 & -0.82 & -0.08 & -0.73 \\
& -0.40 & 0.20 & -0.59 & -0.24 & -0.79 \\
& -0.39 & 0.19 & -0.58 & -0.06 & -0.68
\end{tabular}



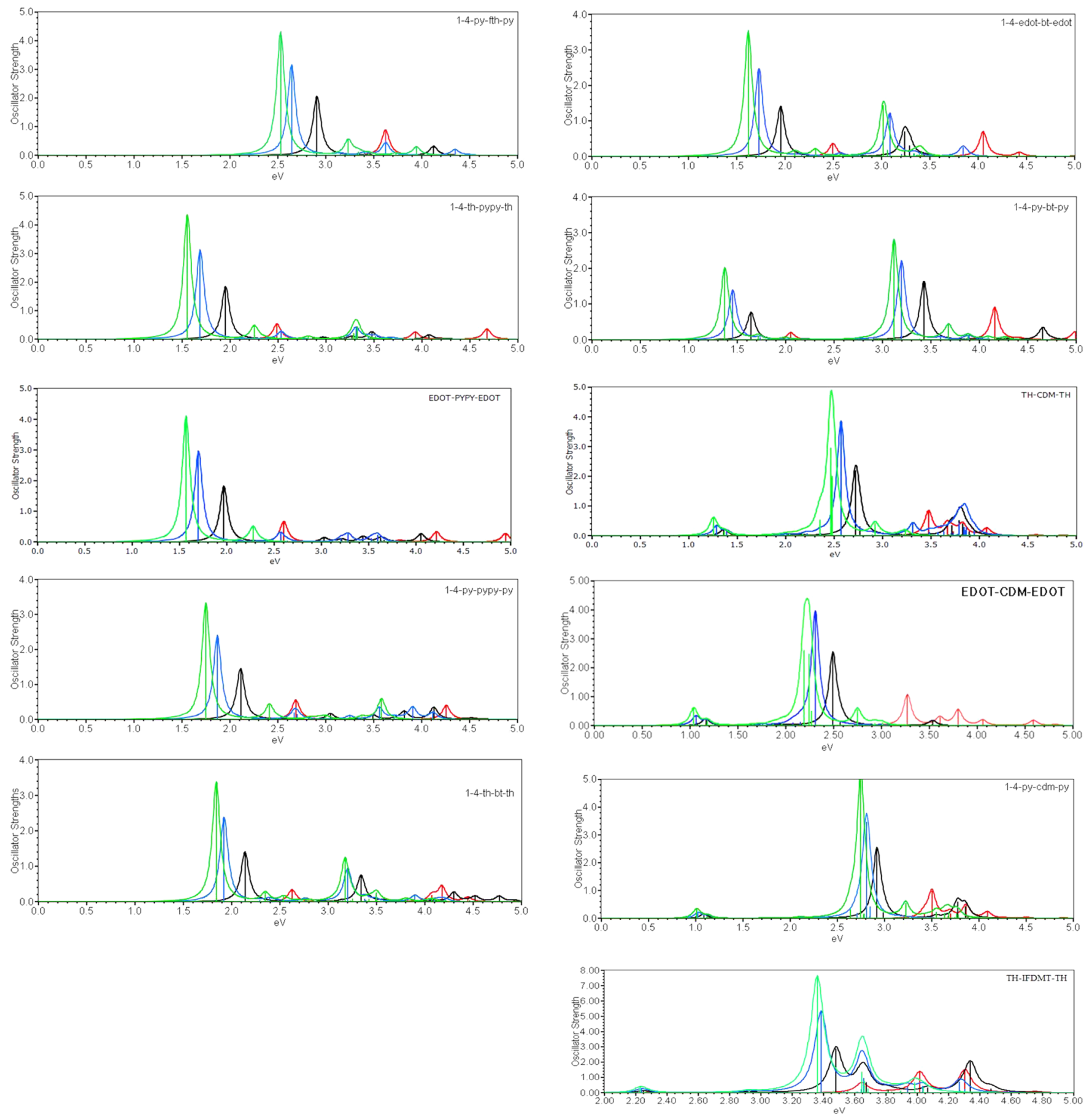

Figure 3. Absorption spectra of monomers (red) through tetramers (green) at B3P86-30\%/6-31G*.

systems with single absorptions. Adding the B3P86-30\% oscillator strengths of the two peaks of 4-TH-BT-TH, 4-EDOT-BT-EDOT, and 4-PY-BT-PY yields values of 4.61, 4.97, and 4.84. The oscillator strength of the $1-1^{\prime}$ transition of 4-PY-FTH-PY is 4.32 . For comparison, the oscillator strengths of the $1-1^{\prime}$ peaks of homopolymers $12-\mathrm{TH}$ and $12-\mathrm{PY}$ are 4.34 and 4.20. Despite the dual absorption, there is thus little increase in total absorbance in the donor-acceptor systems as the two transitions are coupled and obey the Thomas-Reiche-Kuhn sum rule. ${ }^{98-100}$

Nature of the Two Bands. The low energy bands of all systems correspond to HOMO-LUMO or $1 \rightarrow 1^{\prime}$ transitions when the numbering of orbitals starts with " 1 " for the HOMO, " 1 '" for the LUMO and values increase for lower energy occupied orbitals and higher energy unoccupied orbitals. The coefficient of the HOMO-LUMO transition starts with about 0.7 for monomers and decreases with chain length. Thus, the HOMO-LUMO transition contributes less than 50\% to the excited state wave function but there are no additional electron configurations that make similarly strong contributions.

The high energy bands are $1 \rightarrow x^{\prime}$ transitions, where $x$ is the number of repeat units $(n)$ plus one. For IFDMT oligomers, $x=$ $(2 n+1)^{\prime}$ because of the larger number of $\pi$-orbitals in the acceptor. The molecular orbitals involved in these transitions are plotted in Figure 5 for 3-PY-BT-PY. The HOMO orbital looks like those of homopolymers. The next three orbitals, in contrast, are dominated by the LUMO of BT. The following orbital 


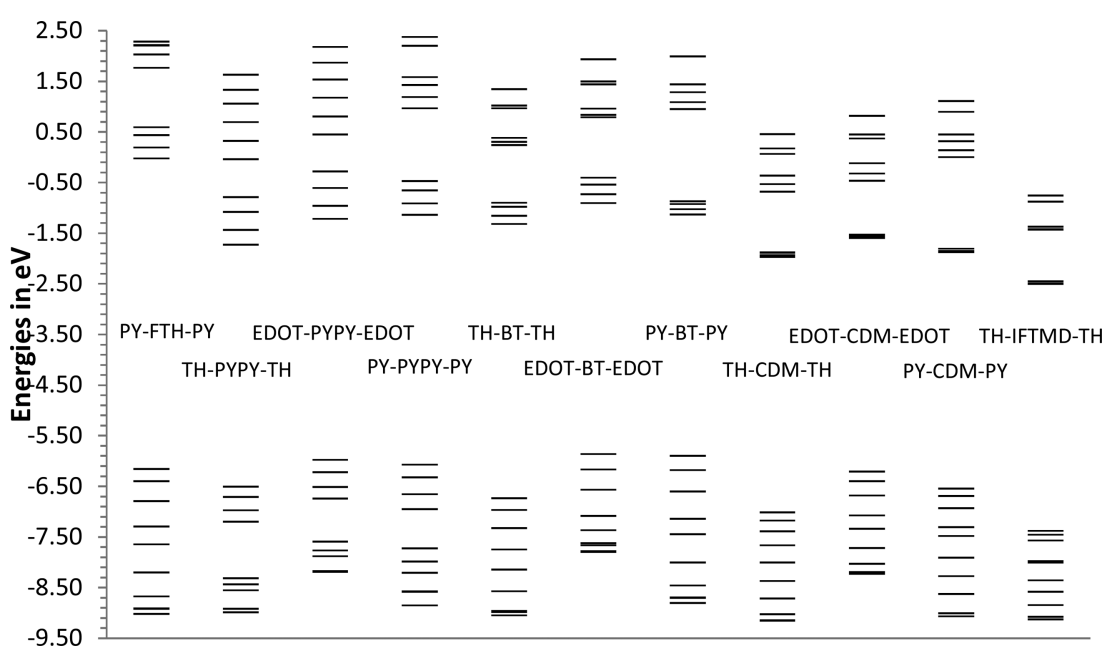

Figure 4. Orbital energies of the 10 highest occupied and 10 lowest unoccupied orbitals of tetramers with wB97XD. With 4 repeat units valence and conduction "bands" consist of four levels each.

$\left(x=(n+1)^{\prime}=4^{\prime}\right)$ resembles the LUMO of thiophene-like homopolymers. The $1-4^{\prime}$ transition of trimers is thus similar in character to the HOMO-LUMO transition of homopolymers, while the $1-1^{\prime}$ transition has charge-transfer character and transfers electrons into partially localized gap states, while the $1 \rightarrow x^{\prime}$ transition has them jump over the localized gap states into the wider bands above. These considerations are valid also for CDM and IFDMT systems where the localization is more pronounced as seen in Figure 6 for 3-TH-IFDMT-TH. PYPY systems (Figure 7) have delocalized HOMOs and LUMOs, only peak in the spectrum and behave in every respect like homopolymers. The remaining systems are intermediate cases.

Extent of Charge Transfer. NBO charges summed over the donors and acceptors are plotted for ground and excited states of tetramers in Figure 8. The charges on the central acceptor units in ground and excited states are summarized in Table 14. Qualitatively, the predictions with the range-separated wB97XD functional and the global hybrid B3P86-30\% are the same, but all charges are smaller with ${ }^{6} B 97 X D$. This seems to be counterintuitive, considering that global hybrids and pure DFT, have a tendency toward over-delocalizing charges to such an extent that $\mathrm{H}_{2}{ }^{+}$dissociates into two $\mathrm{H}^{+1 / 2} \cdot{ }^{101}$ Range-separated functionals ${ }^{88,102}$ were designed to eliminate this problem and tend to localize defects in conjugated systems more than global hybrids. ${ }^{86}$ Since oligomers deviate more from planarity with wB97XD than with B3P86-30\%, ${ }^{86}$ 4-PY-CDM-PY was calculated in $\mathrm{C}_{2 \mathrm{~h}}$ symmetry with both functionals to exclude the possibility that the reduced charge separation with $w B 97 x d$ is caused be different geometries. The charges on the planar structures a virtually identical, only more symmetrically distributed.

In the ground states, the acceptor have charges between -0.03 and -0.28 e. Figure 8 shows that the charges are the same on central and outer rings. According to these ground state charges, PYPY is the strongest electron acceptor, followed by BT. The weakest acceptors are CDM and IFDMT. Thus, the ground state charges do not correlate at all with the EAs of the acceptors. The negative charges on the acceptors increase with increasing strengths of the donor in the order $\mathrm{TH}<\mathrm{EDOT}<\mathrm{PY}$ and therefore correlate with the IPs of the donors.

With TH and EDOT donors, the negative charges on PYPY do not change on excitation, only with PY the negative charge on PYPY increases by 0.1 e. Thus, the $1-1^{\prime}$ transition is not a charge transfer state in PYPY systems. With BT, CDM, and IFDMT, the first excited state involves a significant amount of charge transfer from donor to acceptor, especially on the central rings. The concentration of the charge transfer on the two central rings is somewhat exaggerated in tetramers, however. In the hexamer of PY-BT-PY the charge transfer spreads more evenly over the middle part of the molecule, only the terminal rings do not contribute. The largest charge transfers occur with PY as the donor: 4-PY-BT-PY (0.27 e), 4-PY-CDM-PY (0.26 e), and in 4-THIFDMT-TH $(0.27 \mathrm{e})$. Most of the second excited states also involve charge transfer but to a smaller degree than the first excited states.

Like the ground states, both excited states have higher negative charges on BT than on CDM. Thus, BT is the stronger acceptor in the ground and in the excited state, although CDM has a higher EA. Comparing entries of 4-PY-FTH-PY with 4-THCDM-TH reveals that 4-PY-FTH-PY has the larger charge difference between donor and acceptor in the ground state and the same charge difference as 4-TH-CDM-TH in the excited state. Thus, the appearance of two peaks and the shift in the oscillator strength to the second peak in the absorption spectra cannot be explained with charge transfer between donor and acceptor on excitation.

\section{DISCUSSION}

Comparison of donor-acceptor systems with five different acceptors reveals differences in absorption properties as donoracceptor substitution may lead to either one band at low energy, dual band absorption, or a very weak HOMO-LUMO transition and a prominent high energy peak. Attempts to correlate these absorption properties with EAs (LUMO levels) of the acceptors or charge separations between donors and acceptors in ground or excited states were unsuccessful. Only increasing conduction band localization (Figure 4) correlates with the shift of oscillator strength from the HOMO-LUMO to the higher energy peak.

Although PYPY and BT have almost the same EA, only BT shows a tendency to localization in the conduction band (compare Figures 5 and 7). Thus, energy level differences cannot be the cause for localization. Therefore, the electron densities in the LUMOs of the acceptor units are compared in Figure 9. The trend of decreasing electron densities from PYPY to IFDMT at the carbon atoms to which the donors bind ( $\alpha$-carbons) is clearly visible. 

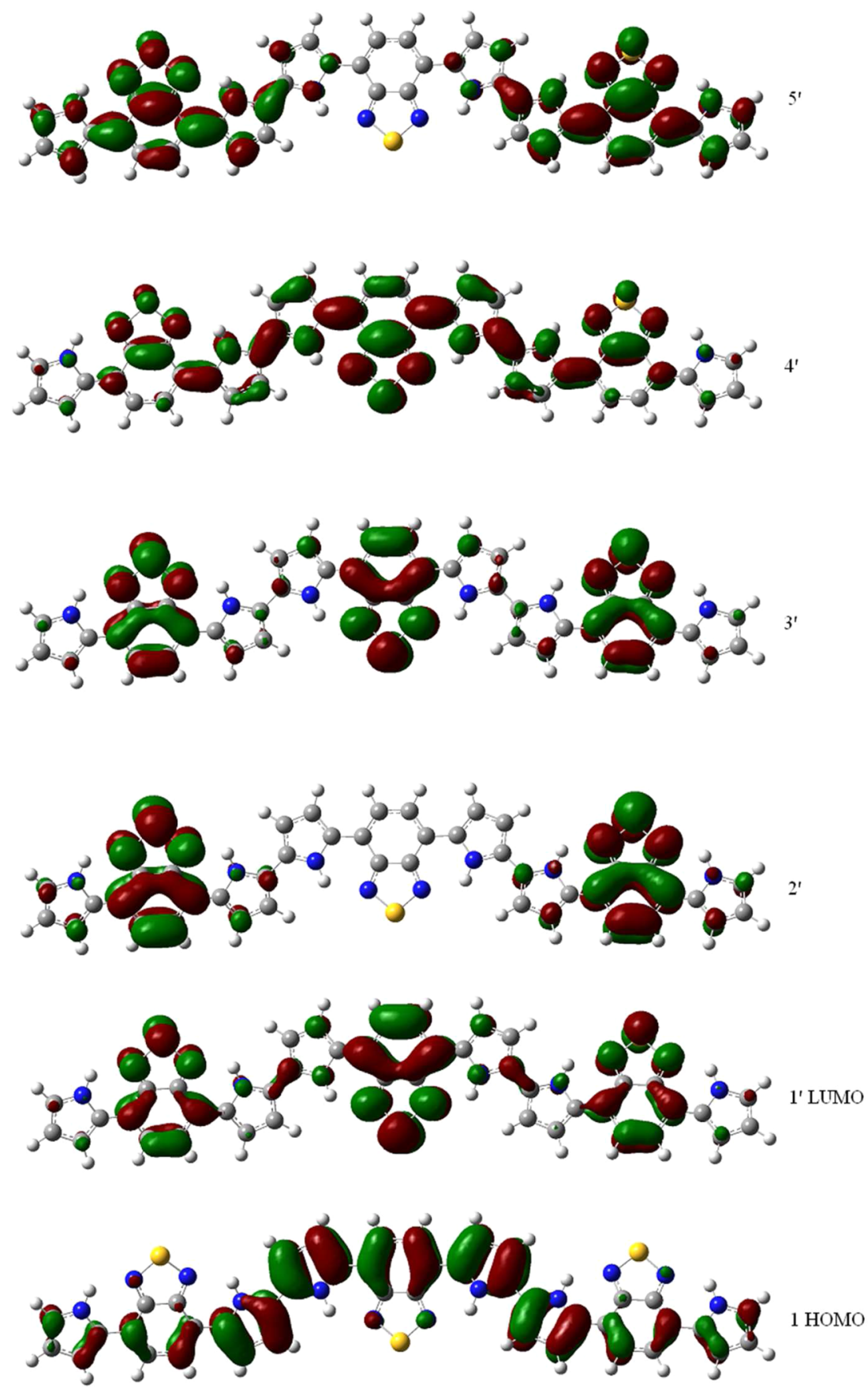

Figure 5. Orbitals of 3-PY-BT-PY.

The LUMO of PYPY has large coefficients (Figure 9) at the $\alpha$-carbons. This leads to large overlap between donor and acceptor orbitals in the conduction band. The consequences are large conduction band dispersions, a single strong absorption at low energy, large red shifts of the UV-absorption band upon chain length increase, and exceptionally large electron mobilities of PYPY systems. ${ }^{95}$ This explains why p-TH-PYPY-TH can be employed as ambipolar material for OFETs ${ }^{95,103}$ and why PYPY systems have started to attract interest for solar cell applications where fullerenes are replaced with PYPY systems as electron conducting materials. ${ }^{104}$ The present theoretical results corroborate excellent light absorption properties of TH-PYPY-TH systems but indicate that open circuit voltages in bulk heterojunction solar cells with PYPY systems as donors may be reduced because of their small band gaps. P-EDOT-PYPY-EDOT in its unsubstituted form would have equally suitable properties but substitution at $\mathrm{N}$ to improve processability leads to loss of planarity, increase of the band gap, and decrease of the band dispersion. PY as the donor starts inducing localization and leads to a larger band gap.

BT gives rise to polymers with two absorptions in the UV-vis spectrum. The occurrence of two absorptions can be traced back to partial localization of the conduction band and reduced spatial overlap between ground and first excited state. ${ }^{68}$ The LUMO of BT (Figure 9) has electron density at the $\alpha$-carbons, but the coefficients are reduced compared to those of PYPY. As a result the EA of p-TH-BT-TH is predicted to be about $0.5 \mathrm{eV}$ smaller than that of p-TH-PYPY-TH, although the monomer EAs differ 


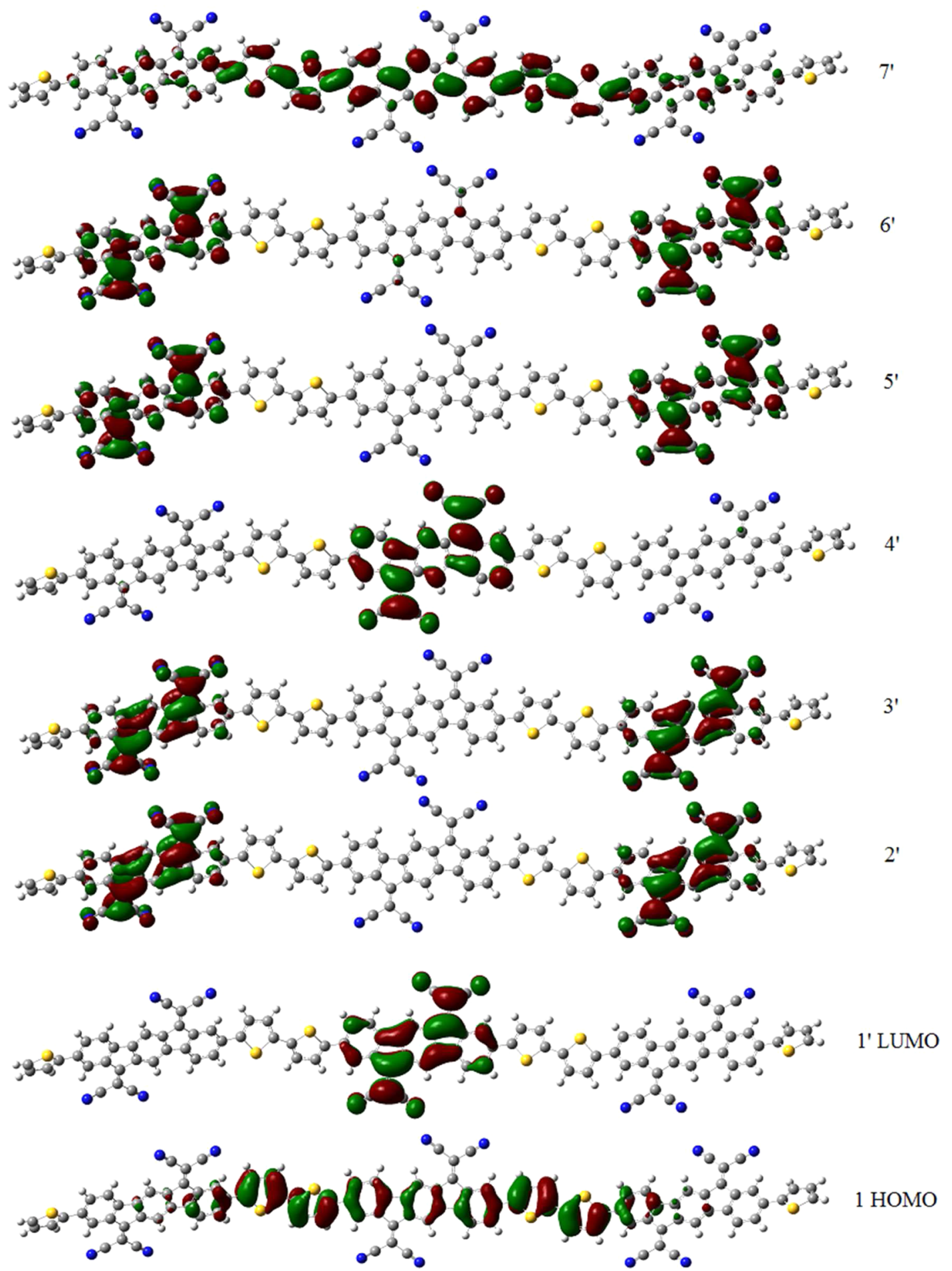

Figure 6. Orbitals of 3-TH-IFDMT-TH.

by only $0.05 \mathrm{eV}$ (Tables 2 and 5). With increasing donor strength and increasing localization of the conduction band (Figure 5), the high energy absorption gains intensity at the expense of the low energy peak. The absorption properties can therefore be tuned by appropriate selection of the donors (EDOT and PY) for producing green polymers ${ }^{72-74,76,78,105,106}$ and $(\mathrm{TH})$ for optimizing light absorption in OPVs, ${ }^{26,27,29-31,34,35,40,41,44,45,49,51-53,55-57,59,107-114}$ as the conduction band is widest with $\mathrm{TH}$ as the donor and the IP of the p-TH-BT-TH is $0.8 \mathrm{eV}$ larger than with PY or EDOT as donors. Thus, $\mathrm{TH}$ is predicted to give larger open circuit voltage, which explains why $\mathrm{TH}$ is the only donor of the three that is used in solar cell applications.

The disadvantage of $\mathrm{BT}$ is the reduced dispersion of the conduction band that is associated with lower electron mobility. In solar cell applications with fullerenes as the electron conducting layer this disadvantage plays no role as confirmed by the fact that majority of all-polymer bulk heterojunction solar cells with power conversion efficiency above $7 \%$ involve BT. ${ }^{113-116}$

Extreme localization of the unoccupied and partial localization of the occupied states is seen with CDM and IFDMT acceptors. 


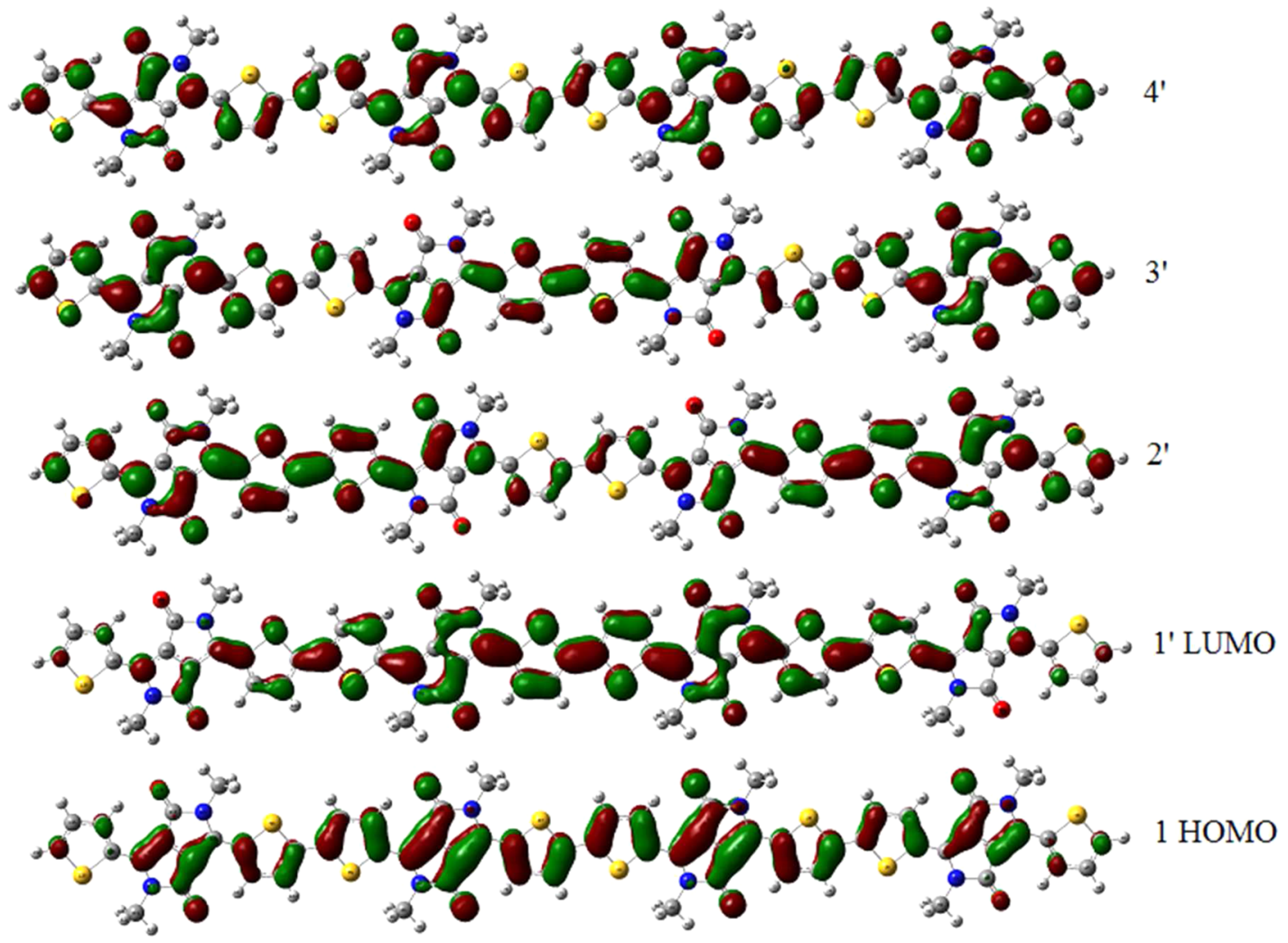

Figure 7. Orbitals of 4-TH-PYPY-TH.

Table 14. Charges on Central Acceptor Units in Ground (GS) and Excited States (ES)

$\begin{array}{lc} & \text { GS B3P86-30\%/wB97XD } \\ \text { PY-FTH-PY } & -0.11 /-0.09 \\ \text { TH-PYPY-TH } & -0.15 /-0.13 \\ \text { EDOT-PYPY-EDOT } & -0.19 /-0.17 \\ \text { PY-PYPY-PY } & -0.28 /-0.24 \\ \text { TH-BT-TH } & -0.10 /-0.08 \\ \text { EDOT-BT-EDOT } & -0.11 /-0.09 \\ \text { PY-BT-PY } & -0.20 /-0.15 \\ \text { TH-CDM-TH } & -0.03 /-0.03 \\ \text { EDOT-CDM-EDOT } & -0.07 /-0.07 \\ \text { PY-CDM-PY } & -0.13 /-0.10 \\ \text { TH-IFDMT-TH } & -0.07 /-0.05\end{array}$

ES 1 B3P $86-30 \% / w B 97 X D$
$-0.23 /-0.19$
$-0.13 /-0.13$
$-0.17 /-0.17$
$-0.38 /-0.34$
$-0.26 /-0.19$
$-0.28 /-0.22$
$-0.47 /-0.38$
$-0.23 /-0.11$
$-0.29 /-0.19$
$-0.39 /-0.24$
$-0.34 /-0.14$
ES 2 B3P86-30\%/wB97XD

For the two close lying transitions the average of the charges was used.

With $\mathrm{C}(\mathrm{CN})_{2}$ groups, the LUMO levels are localized away from the polymer backbone (Figure 9 ) and conjugation is disrupted in the first excited state. The resulting small spatial overlap between ground and excited states leads to very low intensity of the first excited state that neither shifts to lower wavelength nor increases in intensity with chain length of the oligomers. Thus, despite their low band gaps, CDM containing donor-acceptor polymers are expected to lead to low light absorption efficiency in the low energy range. Low electron mobility in the n-doped state ${ }^{63}$ is the consequence of the small conduction band dispersion. The present theoretical analysis predicts also low photocurrents. It is therefore not surprising that CDM polymers have not found application in devices.

Despite the strong localization in the TH-IFDMT-TH system, crystals of the monomer exhibit exceptionally large electron mobility of $0.16 \mathrm{~cm}^{2} /(\mathrm{V} \mathrm{s}) .^{97,117}$ This might appear to contradict the above analysis. However, no improvement in device performance was observed upon polymerization. In fact, all polymers had lower electron mobilities and lower $I_{\text {on }} / I_{\text {off }}$ ratios than the monomers. The strong dependence of the properties on the degree of crystallinity ${ }^{97,117}$ suggests that charge transport occurs through hopping along $\pi$-stacks rather than along the polymer backbone. The theoretical results thus explain why no performance improvement is observed upon polymerization of IFDMT based monomers as polymerization does not enhance optical or electronic properties but decreases crystallinity.

Coming back to the original claim ${ }^{1}$ that donor-acceptor systems may have small band gaps and large bandwidth, it appears the PYPY polymers meet these expectations. However, whether bandwidth increases due to donor-acceptor substitution can only be determined by comparing band widths of copolymers with those of the corresponding homopolymers. PYPY homopolymers have exceptionally wide conduction bands, narrower valence bands, and a vanishingly small band gap. The wave 

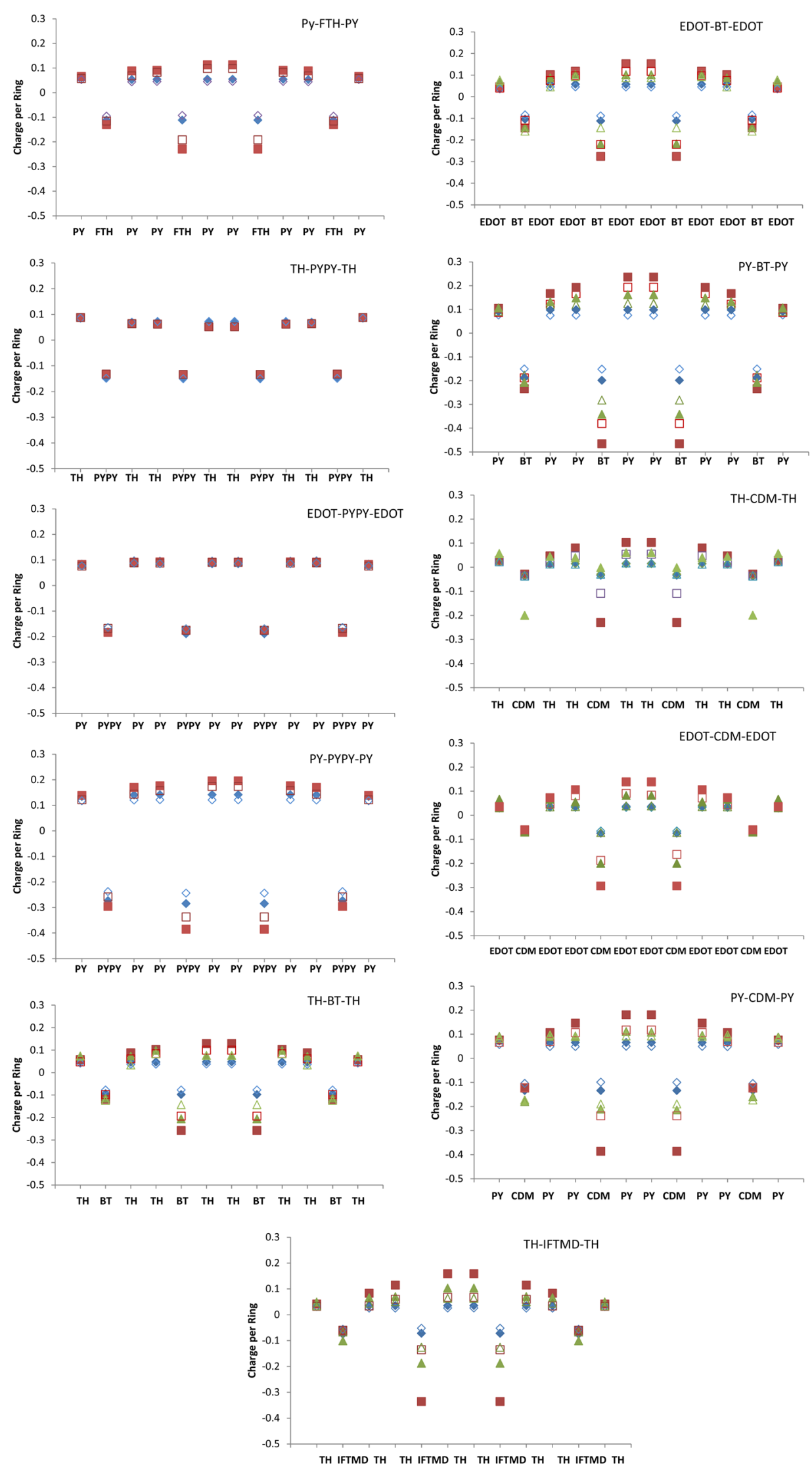

Figure 8. Charges of tetramers in ground state (blue diamonds), first excited state (brown squares), and second excited state (green triangles). Filled symbols B3P86-30\%/6-31G*, open symbols wB97XD/6-31G*. 

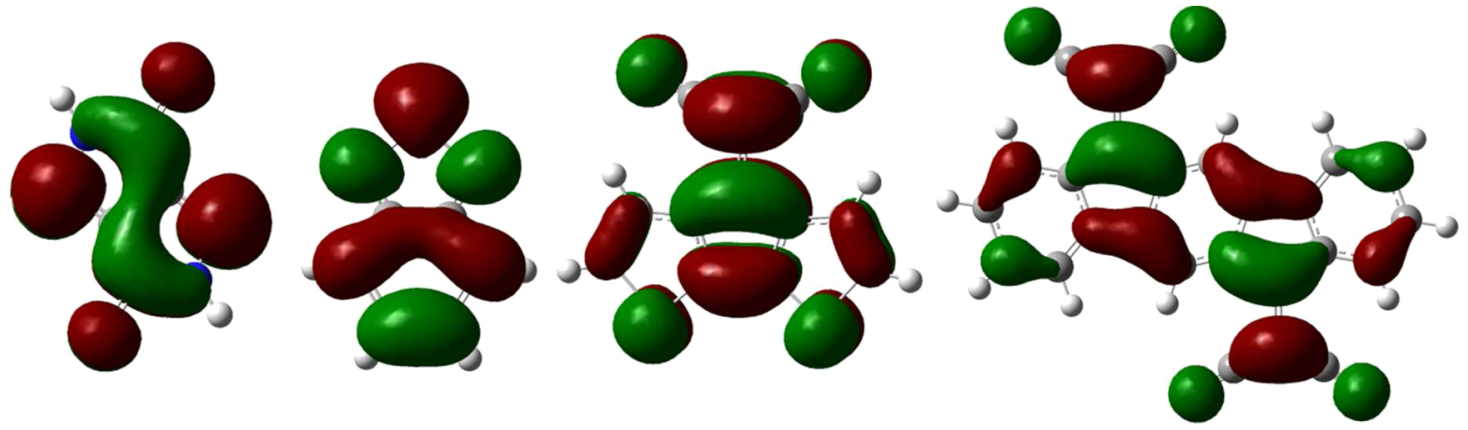

Figure 9. Decreasing electron density at the $\alpha$-carbon atoms in the LUMOs of PYPY, BT, CDM, and IFDMT at B3P86-30\%/6-31G*.

function, however, becomes unstable with increasing chain length and the polymer is probably a biradical. Nonetheless, this shows that, as with other acceptors, donor-acceptor substitution reduces the bandwidth compared to the homopolymer.

\section{CONCLUSIONS}

Theoretical analysis of donor-acceptor systems completely rationalizes the good performance of $\mathrm{p}-\mathrm{TH}-\mathrm{BT}-\mathrm{TH}$ in OPVs, p-TH-PYPY-TH in OFETs, and EDOT-BT-EDOT and PY-BT$\mathrm{PY}$ as green polymers. It also explains the absence of CDM systems in these applications in terms of its low light harvesting capacity in the low energy range and its low electron mobility. That theoretical results without considering morphology lead to a match with the empirical system selection, reveals that device performance is determined to a significant extent by single molecule properties.

Relative oscillator strengths of the charge-transfer and the $\pi-\pi^{*}$ bands of donor-acceptor systems correlate with conduction band localization but not with orbital energy differences between donor and acceptor and not with charge separation in ground or excited states. The dual band absorption of donoracceptor polymers is confirmed to arise from partial conduction band localization caused by reduced overlap between LUMO orbitals of donor and acceptor compared to homopolymers.

The band gap of the donor-acceptor polymers is strongly influenced by the conjugation strength and is not determined alone by donor or acceptor strength as defined by orbital energies. Otherwise PY as the donor would always lead to the smallest band gap, which is not the case.

The most important parameter for the design of donoracceptor systems for specific applications is the electron density distribution in the acceptor unit. To achieve high EAs, high electron mobility, and efficient light absorption in the low energy part of the spectrum, the electron density at the carbon atoms that bind the donors has to be high. Cyano groups that pull the electrons in the acceptor away from backbone have to be avoided.

\section{AUTHOR INFORMATION}

\section{Corresponding Author}

*Tel.: +90 312290 2122. Fax: +90 312266 4068. E-mail: salzner@fen.bilkent.edu.tr.

\section{Notes}

The authors declare no competing financial interest.

\section{ACKNOWLEDGMENTS}

This work was supported by TUBITAK, Grant TBAG 109 T426. The author thanks Aykut Aydin for his help with some of the calculations.

\section{REFERENCES}

(1) Havinga, E. E.; ten Hoeve, W.; Wynberg, H. Alternate DonorAcceptor Small-Band-Gap Semiconducting Polymers; Polysquaraines and Polycroconaines. Synth. Met. 1993, 55-57, 299-306.

(2) Greenham, N. C.; Moratti, S. C.; Bradley, D. D. C.; Friend, R. H.; Holmes, A. B. Efficient Light-Emitting Diodes Based on Polymers with High Electron Affinities. Nature 1993, 365, 628-630.

(3) Friend, R. H.; Greenham, N. C. Electroluminescence in Conducting Polymers. In Handbook of Conducting Polymers; Skotheim, T. A.; Elsenbaumer, R. L.; Reynolds, J. R., Eds.; Marcel Dekker, Inc.: New York, 1998; pp 823-845.

(4) Burroughs, J. H.; Bradley, D. D. C.; Brown, A. R.; Marks, R. N.; Friend, R. H.; Burns, P. L.; Holmes, A. B. Light-Emitting Diodes Based on Conjugated Polymers. Nature 1990, 347, 539-541.

(5) Gustafsson, G.; Gao, Y.; Treacy, G. M.; Klavetter, M.; Colaneri, N.; Heeger, A. J. Flexible Light-Emitting Diodes Made from Soluble Conducting Polymers. Nature 1992, 357, 477.

(6) Berggren, M.; Inganäs, O.; Gustafsson, G.; Andersson, M. R.; Hjertberg, T.; Wennerström, O. Controlling Colour by Voltage in Polymer Light Emitting Diodes. Synth. Met. 1995, 71, 2185-2186.

(7) Onoda, M.; Ohmori, Y.; Kawai, T.; Yoshino, K. Visible-Light Electroluminescent Diodes Using Poly(arylene vinylene). Synth. Met. 1995, 71, 2181-2182.

(8) Yang, Y.; Pei, Q.; Heeger, A. J. Efficient Blue Light-Emitting Diodes from a Soluble Poly(para-phenylene): Internal Field Emission Measurement of the Energy Gap in Semiconducting Polymers. Synth. Met. 1996, 78, 263-267.

(9) Cacialli, F.; Friend, R. H.; Haylett, N.; Daik, R.; Feast, W. J.; dos Santos, D. A.; Brédas, J. L. Efficient Green Light Emitting Diodes from a Phenylated Derivative of Poly ( $p$-phenylene-vinylene). Synth. Met. 1997, 84, 643-644.

(10) Granström, M.; Petritsch, K.; Arias, A. C.; Friend, R. H. High Efficiency Polymer Photodiodes. Synth. Met. 1999, 102, 957-958.

(11) Roman, L. S.; Chen, L. C.; Petterson, L. A. A.; Mammo, W.; Andersson, M. R.; Johansson, M.; Inganäs, O. Multifunctional Polythiophenes in Photodiodes. Synth. Met. 1999, 102, 977-978.

(12) Koezuka, H.; Tsumura, A.; Ando, T. Field-Effect Transistor with Polythiophene Thin Film. Synth. Met. 1987, 18, 699-704.

(13) Burroughs, J. H.; Jones, C. A.; Friend, R. H. New Semiconductor Device Physics in Polymer Diodes and Transistors. Nature 1988, 335, 137.

(14) Garnier, F.; Hajlaoui, R.; Yasser, A.; Srivastava, P. All-Polymer Field-Effect Transistor Realized by Printing Techniques. Science 1994, 265, 1684.

(15) Horowitz, G.; Garnier, F.; Yassar, A.; Hajlaoui, R.; Kouki, F. FieldEffect Transistor Made with a Sexithiophene Single Crystal. Adv. Mater. 1996, 8, 52-53.

(16) Horowitz, G. Organic Field-Effect Transistors. Adv. Mater. 1998, 10, 365-377.

(17) Coropceanu, V.; Brédas, J. L. Organic Transistors: A Polarized Response. Nat. Mater. 2006, 5, 929-930. 
(18) Murphy, A. R; Frechet, J. M. J. Organic Semiconducting Oligomers for Use in Thin Film Transistors. Chem. Rev. 2007, 107, 1066-1096.

(19) Zaumseil, J.; Sirringhaus, H. Electron and Ambipolar Transport in Organic Field-Effect Transistors. Chem. Rev. 2007, 107, 1296-1323.

(20) Chen, S. N.; Heeger, A. J.; Kiss, Z.; MacDiarmid, A. G.; Gau, S. C.; Peebles, D. L. Polyacetylene, $(\mathrm{CH})_{x}$ : Photoelectrochemical Solar Cell. Appl. Phys. Lett. 1980, 36, 96-98.

(21) Yu, G.; Gao, J.; Hummelen, J. C.; Wudl, F.; Heeger, A. J. Polymer Photovoltaic Cells: Enhanced Efficiencies via a Network of Internal Donor-Acceptor Heterojunctions. Science 1995, 270, 1789-1791.

(22) Sirringhaus, H.; Brown, P. J.; Friend, R. H.; Nielsen, M. M.; Bechgaard, K.; Langeveld-Voss, B. M. W.; Spiering, A. J. H.; Janssen, R. A. J.; Meijer, E. W.; Herwig, P.; de Leeuw, D. M. Two-Dimensional Charge Transport in Self-Organized, High-Mobility Conjugated Polymers. Nature 1999, 401, 685.

(23) Hagfeldt, A.; Gratzel, M. Molecular Photovoltaics. Acc. Chem. Res. 2000, 33, 269-277.

(24) Güneş, S.; Neugebauer, H.; Sariçiftci, N. S. Conjugated PolymerBased Organic Solar Cells. Chem. Rev. 2007, 107, 1324-1338.

(25) Bredas, J.-L.; Norton, J. E.; Cornil, J.; Coropceanu, V. Molecular Understanding of Organic Solar Cells: The Challenges. Acc. Chem. Res. 2009, 42, 1691-1699.

(26) Inganas, O.; Zhang, F.; Andersson, M. R. Alternating Polyfluorenes Collect Solar Light in Polymer Photovoltaics. Acc. Chem. Res. 2009, 42, 1731-1739.

(27) Delgado, J. L.; Bouit, P.-A.; Filippone, S.; Herranz, M. A.; Martin, N. Organic Photovoltaics: A Chemical Approach. Chem. Commun. 2010, $46,4853$.

(28) Morana, M.; Koers, P.; Waldauf, C.; Koppe, M.; Muehlbacher, D.; Denk, P.; Scharber, M.; Waller, D.; Brabec, C. Organic Field-Effect Devices as Tool to Characterize the Bipolar Transport in PolymerFullerene Blends: The Case of P3HT-PCBM. Adv. Funct. Mater. 2007, $17,3274-3283$.

(29) Hou, J.; Chen, H.-Y.; Zhang, S.; Li, G.; Yang, Y. Synthesis, Characterization, and Photovoltaic Properties of a Low Band Gap Polymer Based on Silole-Containing Polythiophenes and 2,1,3Benzothiadiazole. J. Am. Chem. Soc. 2008, 130, 16144-16145.

(30) Hou, J.; Park, M.-H.; Zhang, S.; Yao, Y.; Chen, L.-M.; Li, J.-H.; Yang, Y. Bandgap and Molecular Energy Level Control of Conjugated Polymer Photovoltaic Materials Based on Benzo[1,2-b:4,5- $\left.b^{\prime}\right]$ dithiophene. Macromolecules 2008, 41, 6012-6018.

(31) Biniek, L.; Chochos, C. L.; Leclerc, N.; Hadziioannou, G.; Kallitsis, J. K.; Bechara, R.; Leveque, P.; Heiser, T. A [3,2b] thienothiophene-alt-benzothiadiazole Copolymer for Photovoltaic Applications: Design, Synthesis, Material Characterization, and Device Performances. J. Mater. Chem. 2009, 19, 4946-4951.

(32) Huo, L.; Hou, J.; Chen, H.-Y.; Zhang, S.; Jiang, Y.; Chen, T. L.; Yang, Y. Bandgap and Molecular Level Control of the Low-Bandgap Polymers Based on 3,6-Dithiophen-2-yl-2,5-dihydropyrrolo[3,4-c]pyrrole-1,4-dione toward Highly Efficient Polymer Solar Cells. Macromolecules 2009, 42, 6564-6571.

(33) Mondal, R.; Ko, S.; Norton, J. E.; Miyaki, N.; Becerril, H. A.; Verploegen, E.; Toney, M. F.; Bredas, J.-L.; McGehee, M. D.; Bao, Z. Molecular Design for Improved Photovoltaic Efficiency: Band Gap and Absorption Coefficient Engineering. J. Mater. Chem. 2009, 19, 71957197.

(34) Wang, E.; Wang, M.; Wang, L. X.; Duan, C.; Zhang, J.; Cai, W.; $\mathrm{He}, \mathrm{C} . ; \mathrm{Wu}, \mathrm{H} . ; \mathrm{Cao}$, Y. Donor Polymers Containing Benzothiadiazole and Four Thiophene Rings in Their Repeating Units with Improved Photovoltaic Performance. Macromolecules 2009, 42, 4410-4415.

(35) Zhang, S.; Guo, Y.; Fan, H.; Liu, Y.; Chen, H. Y.; Yang, G.; Zhan, X.; Liu, Y.; Li, Y.; Yang, Y. Low Bandgap p-Conjugated Copolymers Based on Fused Thiophenes and Benzothiadiazole: Synthesis and Structure-Property Relationship Study. J. Polym. Sci. A 2009, 47, 54985508 .

(36) Zoombelt, A. P.; Fonrodona, M.; Turbiez, M. G. R.; Wienk, M. M.; Janssen, R. A. J. Synthesis and photovoltaic performance of a series of small band gap polymers. J. Mater. Chem. 2009, 19, 5336-5342.
(37) Zoombelt, A. P.; Fonrodona, M.; Wienk, M. M.; Sieval, A. B.; Hummelen, J. C.; Janssen, R. A. J. Photovoltaic Performance of an Ultrasmall Band Gap Polymer. Org. Lett. 2009, 11, 903-906.

(38) Zou, Y.; Gendron, D.; Neagu-Plesu, R.; Leclerc, M. Synthesis and Characterization of New Low-Bandgap Diketopyrrolopyrrole-Based Copolymers. Macromolecules 2009, 42, 6361-6364.

(39) Baran, D.; Balan, A.; Esteban, B.-M.; Neugebauer, H.; Sariciftci, S.; Toppare, L. Spectroelectrochemical and Photovoltaic Characterization of a Solution-Processable n- and p-Type Dopable Pyrrole-Bearing Conjugated Polymer. Macromol. Chem. Phys. 2010, 211, 2602-2620.

(40) Chen, Y.-C.; Yu, C.-Y.; Fan, Y.-L.; Hung, L.-I.; Chen, C.-P.; Ting, C. Low-Bandgap Conjugated Polymer for High Efficient Photovoltaic Applications. Chem. Commun. 2010, 46, 6503-6505.

(41) Ding, P.; Chu, C.-C.; Liu, B.; Peng, B.; Zou, Y.; He, Y.; Zhou, K.; Hsu, C.-S. A High-Mobility Low-Bandgap Copolymer for Efficient Solar Cells. Macromol. Chem. Phys. 2010, 211, 2555-2561.

(42) Karsten, B. P.; Bouwer, R. K. M.; Hummelen, J. C.; Williams, R. M.; Janssen, R. A. J. Charge Separation and Recombination in Small Band Gap Oligomer-Fullerene Triads. J. Phys. Chem. B 2010, 114, 14149-14156.

(43) Mondal, R.; Ko, S.; Bao, Z. Fused Aromatic Thienopyrazines: Structure, Properties and Function. J. Mater. Chem. 2010, 20, 1056810576.

(44) Price, S. C.; Steward, A. C.; You, W. Low Band Gap Polymers Based on Benzo[1,2-b:4,5-b0]dithiophene: Rational Design of Polymers Leads to High Photovoltaic Performance. Macromolecules 2010, 43, 4609-4612.

(45) Song, J.; Zhang, C.; Li, C.; Li, W.; Qin, R.; Li, B.; Liu, Z.; Bo, Z. Conjugated Polymers with Broad Absorption: Synthesis and Application in Polymer Solar Cells. J. Polym. Sci. A 2010, 48, 25712578.

(46) Zhang, G.; Fu, Y.; Zhang, Q.; Xie, Z. Benzo[1,2-b:4,5b0]dithiophene-Dioxopyrrolothiophen Copolymers for High Performance Solar Cells. Chem. Commun. 2010, 46, 4997-4999.

(47) Zhang, Y.; Hau, S. K.; Yip, H.-L.; Sun, Y.; Acton, O.; Jen, A. K.-Y. Efficient Polymer Solar Cells Based on the Copolymers of Benzodithiophene and Thienopyrroledione. Chem. Mater. 2010, 22, 2696-2698.

(48) Zhou, E.; Cong, J.; Tajima, K.; Yang, C.; Hashimoto, K. Synthesis and Photovoltaic Properties of Donor-Acceptor Copolymer Based on Dithienopyrrole and Thienopyrroledione. Macromol. Chem. Phys. 2010, 212, 305-310.

(49) Zhou, E.; Cong, J.; Yamakawa, S.; Wei, Q.; Nakamura, M.; Tajima, K.; Yang, C.; Hashimoto, K. Synthesis of Thieno[3,4-b]pyrazine-Based and 2,1,3-Benzothiadiazole-Based Donor-Acceptor Copolymers and Their Application in Photovoltaic Devices. Macromolecules 2010, 43, 2873-2879.

(50) Zou, Y.; Najari, A.; Berrouard, P.; Beaupre, S.; Reda Aich, B.; Tao, Y.; Leclerc, M. A Thieno[3,4-c]pyrrole-4,6-dione-Based Copolymer for Efficient Solar Cells. J. Am. Chem. Soc. 2010, 132, 5330-5331.

(51) Boudreault, P.-L. T.; Najari, A.; Leclerc, M. Processable LowBandgap Polymers for Photovoltaic Applications. Chem. Mater. 2011, 23, 456-469.

(52) Facchetti, A. $\pi$-Conjugated Polymers for Organic Electronics and Photovoltaic Cell Applications. Chem. Mater. 2011, 23, 733-758.

(53) Falzon, M.-F.; Wienk, M. M.; Janssen, R. A. J. Designing Acceptor Polymers for Organic Photovoltaic Devices. J. Phys. Chem. C 2011, 115, $3178-3187$

(54) Jiang, J.-M.; Yang, P.-A.; Chen, H.-C.; Wei, K.-H. Synthesis, Characterization, And Photovoltaic Properties of a Low-Bandgap Copolymer Based on 2,1,3-Benzooxadiazole. Chem. Commun. 2011, 47, 8877-8879.

(55) Patil, A. V.; Lee, W.-H.; Kim, K.; Lee, Y.-S.; Kang, I.-N.; Lee, S.-H. Synthesis and Characterization of Dithienothiophene/Benzothiadiazole Based Low Band Gap Donor-Acceptor Copolymers for Bulk Hetero Junction Photovoltaic Cells. Synth. Met. 2011, 161, 1838-1844.

(56) Price, S. C.; Stuart, A. C.; Yang, L.; Zhou, H.; You, W. Fluorine Substituted Conjugated Polymer of Medium Band Gap Yields 7\% 
Efficiency in Polymer-Fullerene Solar Cells. J. Am. Chem. Soc. 2011, 133, 4625-4631.

(57) Sonar, P.; Williams, E. L.; Singh, S. P.; Dodabalapur, A. Thiophene-Benzothiadiazole-Thiophene (D-A-D) Based Polymers: Effect of Donor/Acceptor Moieties Adjacent to D-A-D Segment on Photophysical and Photovoltaic Properties. J. Mater. Chem. 2011, 21, 10532-10541.

(58) Zhang, L.; Tajima, K.; Hashimoto, K. Low Bandgap Polymers Based on Regioregular Oligothiophenes Linked with Electron Accepting Units. Macromolecules 2011, 44, 4222-4229.

(59) Zhou, H.; Yang, L.; Stuart, A. C.; Price, S. C.; Liu, S.; You, W. Development of Fluorinated Benzothiadiazole as a Structural Unit for a Polymer Solar Cell of 7\% Efficiency. Angew. Chem. 2011, 123, 30513054.

(60) Salzner, U. Does the Donor-Acceptor Concept Work for Designing Synthetic Metals? 1. Theoretical Investigation of Poly(3cyano-3'-hydroxybithiophene). J. Phys. Chem. B 2002, 106, 9214-9220.

(61) Salzner, U.; Karalti, O.; Durdagi, S. Does the Donor-Acceptor Concept Work for Designing Synthetic Metals? III. Theoretical Investigation of Copolymers between Quinoid Acceptors and Aromatic Donors. J. Mol. Model. 2006, 12, 687-701.

(62) Salzner, U.; Köse, M. E. Does the Donor-Acceptor Concept Work for Designing Synthetic Metals? 2. Theoretical Investigation of Copolymers of 4 -(Dicyanomethylene- $4 H$-cyclopenta[2,1-b:3,4- $\left.b^{\prime}\right]$ dithiophene and 3,4-(Ethylenedioxy)thiophene. J. Phys. Chem. B 2002, 106, 9221-9226.

(63) Huang, H.; Pickup, P. G. A Donor-Acceptor Conducting Copolymer with a Very Low Band Gap and High Intrinsic Conductivity. Chem. Mater. 1998, 10, 2212-2216.

(64) Berlin, A.; Zotti, G.; Zecchin, S.; Schiavon, G.; Vercelli, B.; Zanelli, A. New Low-Gap Polymers from 3,4-Ethylenedioxythiophene-BisSubstituted Electron-Poor Thiophenes. The Roles of Thiophene, Donor-Acceptor Alternation, and Copolymerization in Intrinsic Conductivity. Chem. Mater. 2004, 16, 3667-3676.

(65) Yang, C.; Cho, S.; Chiechi, R. C.; Walker, W.; Coates, N. E.; Moses, D.; Heeger, A. J.; Wudl, F. Visible-Near Infrared Absorbing Dithienylcyclopentadienone-Thiophene Copolymers for Organic Thin-Film Transistors. J. Am. Chem. Soc. 2008, 130, 16524-16526.

(66) Dutta, T.; Woody, K. B.; Parkin, S. R.; Watson, M. D.; Gierschner, J. Conjugated Polymers with Large Effective Stokes Shift: Benzobisdioxole-Based Poly(phenylene ethynylene)s. J. Am. Chem. Soc. 2009, 131, 17321-17327.

(67) Cornil, J.; Gueli, I.; Dkhissi, A.; Sancho-Garcia, J.; Hennebicq, E.; Calbert, J.; Lemaur, V.; Beljonne, D.; Brédas, J. Electronic and optical properties of polyfluorene and fluorene-based copolymers: A quantumchemical characterization. J. Chem. Phys. 2003, 118, 6615.

(68) Jespersen, K. G.; Beenken, W. J. D.; Zaushisyn, Y.; Yartsev, A.; Andersson, M.; Pullerits, T.; Sundström, V. The Electric States of Polyfluorene Coploymers with Alternating Donor-Acceptor Units. J. Chem. Phys. 2004, 121, 12613-12617.

(69) Hung, Y.-C.; Jiang, J.-C.; Chao, C.-Y.; Su, W.-F.; Lin, S.-T. Theoretical Study on the Correlation between Band Gap, Bandwidth, and Oscillator Strength in Fluorene-Based Donor-Acceptor Conjugated Copolymers. J. Phys. Chem. B 2009, 113, 8268-8277.

(70) Sonmez, G.; Shen, C. K. F.; Rubin, Y.; Wudl, F.; Red, A. Green and Blue (RGB) Polymeric Electrochromic Device (PECD): The Dawning of the PECD Era. Angew. Chem., Int. Ed. Engl. 2004, 43, 1498-1502.

(71) Sönmez, G.; Shen, C. K. F.; Rubin, Y.; Wudl, F. The Unusual Effect of Bandgap Lowering by $\mathrm{C}_{60}$ on a Conjugated Polymer. Adv. Mater. 2005, 17, 897-900.

(72) Sonmez, G.; Sonmez, H. B.; Shen, C. K. F.; Jost, R. W.; Rubin, Y.; Wudl, F. A Processable Green Polymeric Electrochromic. Macromolecules 2005, 38, 669-675.

(73) Durmus, A.; Gunbas, G. E.; Camurlu, P.; Toppare, L. A Neutral State Green Polymer with a Superior Transmissive Light Blue Oxidized State. Chem. Commun. 2007, 3246-3248.

(74) Durmus, A.; Gunbas, G. E.; Toppare, L. New, Highly Stable Electrochromic Polymers from 3,4-Ethylenedioxythiophene-Bis-Sub- stituted Quinoxalines toward Green Polymeric Materials. Chem. Mater. 2007, 19, 6247-6251.

(75) Balan, A.; Gunbas, G.; Durmus, A.; Toppare, L. Donor-Acceptor Polymer with Benzotriazole Moiety: Enhancing the Electrochromic Properties of the "Donor Unit". Chem. Mater. 2008, 20, 7510-7513.

(76) Gunbas, G. E.; Durmus, A.; Toppare, L. A Unique Processable Green Polymer with a Transmissive Oxidized State for Realization of Potential RGB-Based Electrochromic Device Applications. Adv. Funct. Mater. 2008, 18, 2026-2030.

(77) Gunbas, G. E.; Durmus, A.; Toppare, L. Could Green be Greener? Novel Donor-Acceptor-Type Electrochromic Polymers: Towards Excellent Neutral Green Materials with Exceptional Transmissive Oxidized States for Completion of RGB Color Space. Adv. Mater. 2008, 20, 691-695.

(78) Baran, D.; Oktem, G.; Celebi, S.; Toppare, L. Neutral-State Green Conjugated Polymers from Pyrrole Bis-Substituted Benzothiadiazole and Benzoselenadiazole for Electrochromic Devices. Macromol. Chem. Phys. 2011, 212, 799-805.

(79) Oktem, G.; Balan, A.; Baran, D.; Toppare, L. Donor-Acceptor Type Random Copolymers for Full Visible Light Absorption. Chem. Commun. 2011, 47, 3933-3935.

(80) Beaujuge, P. M.; Amb, C. M.; Reynolds, J. R. Spectral Engineering in $\pi$-Conjugated Polymers with Intramolecular Donor-Acceptor Interactions. Acc. Chem. Res. 2010, 43, 1396-1407.

(81) Reed, E. A.; Curtiss, L. A.; Weinhold, F. NBO. Chem. Rev. 1988, $88,899$.

(82) Becke, A. D. Density-Functional Thermochemistry. III. The Role of Exact Exchange. J. Chem. Phys. 1993, 98, 5648-5652.

(83) Perdew, J. P. Density Functional Approximation for the Correlation Energy of the Inhomogeneous Electron Gas. Phys. Rev. B 1986, 33, 8822-8824.

(84) Salzner, U.; Pickup, P. G.; Poirier, R. A.; Lagowski, J. B. Accurate Method for Obtaining Band Gaps in Conducting Polymers Using a DFT/Hybrid Approach. J. Phys. Chem. A 1998, 102, 2572-2578.

(85) Chai, J.-D.; Head-Gordon, M. Long-Range Corrected Hybrid Density Functionals with Damped Atom-Atom Dispersion Corrections. Phys. Chem. Chem. Phys. 2008, 10, 6615-6620.

(86) Salzner, U.; Aydin, A. Improved Prediction of Properties of $\pi$ Conjugated Oligomers with Range-Separated Hybrid Density Functionals. J. Chem. Theory Comput. 2011, 7, 2568-2583.

(87) Livshits, E.; Baer, R. A Well-Tempered Density Functional Theory of Electrons in Molecules. Phys. Chem. Chem. Phys. 2007, 9, $2932-2941$.

(88) Baer, R.; Livshits, E.; Salzner, U. Tuned Range-Separated Hybrids in Density Functional Theory. Annu. Rev. Phys. Chem. 2010, 61, 85-109.

(89) Kronik, L.; Stein, T.; Refaely-Abramson, S.; Baer, R. Excitation Gaps of Finite-Sized Systems from Optimally Tuned Range-Separated Hybrid Functionals. J. Chem. Theory Comput. 2011, 8, 1515-1531.

(90) Refaely-Abramson, S.; Baer, R.; Kronik, L. Fundamental and excitation gaps in molecules of relevance for organic photovoltaics from an optimally tuned range-separated hybrid functional. Phys. Rev. B 2011, 84, 075144.

(91) Garza, A. J.; Osman, O. I.; Wazzan, N. A.; Khan, S. B.; Asiri, A. M.; Scuseria, G. E. A Computational Study of the Nonlinear Optical Properties of Carbazole Derivatives: Theory Refines Experiment. Theor. Chem. Acc. 2014, 133, 1458.

(92) Dierksen, M.; Grimme, S. Density Functional Calculations of the Vibronic Structure of Electronic Absorption Spectra. J. Chem. Phys. 2004, 120, 3544-3554.

(93) Dierksen, M.; Grimme, S. The Vibronic Structure of Electronic Absorption Spectra of Large Molecules: A Time-Dependent Density Functional Study on the Influence of "Exact" Hartree-Fock Exchange. J. Phys. Chem. A 2004, 108, 10225-10237.

(94) Allouche, A.-R. GabEdit, 2.1.8; 2007.

(95) Kanimozhi, C.; Yaacobi-Gross, N.; Chou, K. W.; Amassian, A.; Anthopoulos, T. D.; Patil, S. Diketopyrrolopyrrole-Diketopyrrolopyrrole-Based Conjugated Copolymer for High-Mobility Organic FieldEffect Transistors. J. Am. Chem. Soc. 2012, 134, 16532-16535. 
(96) van Mullekom, H. A. M.; Vekemans, J. A. J. M.; Meijer, E. W. Band-Gap Engineering of Donor-Acceptor $\pi$-Conjugated Polymers. Chem.-Eur. J. 1998, 4, 1235-1243.

(97) Usta, H.; Risko, C.; Wang, Z.; Huang, H.; Deliomeroglu, M. K.; Zhukhovitskiy, A.; Facchetti, A.; Marks, T. J. Design, Synthesis, and Characterization of Ladder-Type Molecules and Polymers. Air-Stable, Solution-Processable n-Channel and Ambipolar Semiconductors for Thin-Film Transistors via Experiment and Theory. J. Am. Chem. Soc. 2009, 131, 5586-5608.

(98) Kuhn, W. Über die Gesamtstarke der von einem Zustande ausgehenden Absorptionslinien. Z. Phys. 1925, 33, 408-412.

(99) Reiche, F.; Thomas, W. Über die Zahl der Dispersionselektronen, die einem stationaren Zustand zugeordnet sind. Z. Phys. 1925, 34, 510525 .

(100) Thomas, W. Über die Zahl der Dispersionselektronen, die einem stationären Zustande zugeordnet sind. Naturwiss. 1925, 13, 627.

(101) Cohen, A. J.; Mori-Sanchez, P.; Yang, W. Insights into Current Limitations of Density Functional Theory. Science 2008, 321, 792-794.

(102) Iikura, H.; Tsuneda, T.; Yanai, T.; Hirao, K. A Long-Range Correction Scheme for Generalized-Gradient-Approximation Exchange Functionals. J. Chem. Phys. 2001, 115, 3540-3544.

(103) Bijleveld, J. C.; Zoombelt, A. P.; Mathijssen, S. G. J.; Wienk, M. M.; Turbiez, M.; de Leeuw, D. M.; Janssen, R. A. J. Poly(diketopyrrolopyrrole-terthiophene) for Ambipolar Logic and Photovoltaics. J. Am. Chem. Soc. 2009, 131, 16616-16617.

(104) Li, W.; Roelofs, W. S. C.; Turbiez, M.; Wienk, M. M.; Janssen, R. A. J. Polymer Solar Cells with Diketopyrrolopyrrole Conjugated Polymers as the Electron Donor and Electron Acceptor. Adv. Mater. 2014, 26, 3304-3309.

(105) Algi, F.; Cihaner, A. An Ambipolar Neutral State Green Polymeric Electrochromic. Org. Electronics 2009, 10, 704-710.

(106) Gunbas, G.; Toppare, L. Green As It Gets; Donor-Acceptor type Polymers as the Key to Realization of RGB Based Polymer Display Devices. Macromol. Symp. 2010, 297, 79-86.

(107) Ahmed, E.; Kim, F. S.; Xin, H.; Jenekhe, S. A. Benzobisthiazolea-Thiophene Copolymer Semiconductors: Synthesis, Enhanced Stability, Field-Effect Transistors, and Efficient Solar Cells. Macromolecules 2009, 42, 8615-8618.

(108) Nielsen, C. B.; Schroeder, B. C.; Hadipour, A.; Rand, B. P.; Watkins, S. E.; McCulloch, I. A Benzotrithiophene-Based Low Band Gap Polymer for Polymer Solar Cells with High Open-Circuit Voltage. J. Mater. Chem. 2011, 21, 17642-17645.

(109) Zhang, F.; Wu, D.; Xu, Y.; Feng, X. Thiophene-Based Conjugated Oligomers for Organic Solar Cells. J. Mater. Chem. 2011, 21, 17590-17600.

(110) Bundgaard, E.; Krebs, F. C. Low-Band-Gap Conjugated Polymers based on Thiophene, Benzothiadiazole, and Benzobis(thiadiazole). Macromolecules 2006, 39, 2823-2831.

(111) Won, S. S.; Sung, C. K.; Lee, S.-J.; Jeon, H.-S.; Kim, M.-K.; Naidu, B. V. K.; Jin, S.-H.; Lee, J.-K.; Lee, J. W.; Gal, Y.-S. Synthesis and Photovoltaic Properties of a Low-Band-Gap Polymer Consisting of Alternating Thiophene and Benzothiadiazole Derivatives for BulkHeterojunction and Dye-Sensitized Solar Cells. J. Polym. Sci. A 2007, 45, 1394-1402.

(112) Zhang, Y.; Chien, S.-C.; Chen, K.-S.; Yip, H.-L.; Sun, Y.; Davies, J. A.; Chen, F.-C.; Jen, A. K. Y. Increased Open Circuit Voltage in Fluorinated Benzothiadiazole-Based Alternating Conjugated Polymers. Chem. Commun. 2011, 47, 11026-11028.

(113) Li, Y. Molecular Design of Photovoltaic Materials for Polymer Solar Cells: Toward Suitable Electronic Energy Levels and Broad Absorption. Acc. Chem. Res. 2012, 45, 723-733.

(114) Zhang, M.; Gu, Y.; Guo, X.; Liu, F.; Zhang, S.; Huo, L.; Russell, T. P.; Hou, J. Efficient Polymer Solar Cells Based on Benzothiadiazole and Alkylphenyl Substituted Benzodithiophene with a Power Conversion Efficiency over 8\%. Adv. Mater. 2013, 25, 4944-4949.

(115) Wang, N.; Chen, Z.; Wei, W.; Jiang, Z. Fluorinated Benzothiadiazole-Based Conjugated Polymers for High-Performance Polymer Solar Cells without Any Processing Additives or PostTreatments. J. Am. Chem. Soc. 2013, 135, 17060-17068.
(116) Olivier, Y.; Niedzialek, D.; Lemaur, V.; Pisula, W.; Müllen, K.; Koldemir, U.; Reynolds, J. R.; Lazzaroni, R.; Cornil, J.; Beljonne, D. 25th Anniversary Article: High-Mobility Hole and Electron Transport Conjugated Polymers: How Structure Defines Function. Adv. Mater. 2014, 26, 2119-2136.

(117) Usta, H.; Facchetti, A.; Marks, T. J. Air-Stable, SolutionProcessable n-Channel and Ambipolar Semiconductors for Thin-Film Transistors Based on the Indenofluorenebis(dicyanovinylene) Core. J. Am. Chem. Soc. 2008, 130, 8580-8581. 